\title{
Heat Transfer and Thermodynamic Performance of a Parabolic Trough Receiver with Centrally Placed Perforated Plate Inserts
}

\author{
Aggrey Mwesigye ${ }^{1}$, Tunde Bello-Ochende ${ }^{2 \dagger}$, Josua P. Meyer ${ }^{1}$ \\ ${ }^{1 .}$ Department of Mechanical and Aeronautical Engineering, University of Pretoria, Private Bag X20, Hatfield 0028, \\ South Africa \\ ${ }^{2}$ Department of Mechanical Engineering, University of Cape Town \\ Private Bag X3, Rondebosch 7701, South Africa
}

\begin{abstract}
In this paper, a numerical investigation of thermal and thermodynamic performance of a receiver for a parabolic trough solar collector with perforated plate inserts is presented. The analysis was carried out for different perforated plate geometrical parameters including dimensionless plate orientation angle, the dimensionless plate spacing, and the dimensionless plate diameter. The Reynolds number varies in the range $1.02 \times 10^{4} \leq R e \leq 7.38 \times 10^{5}$ depending on the heat transfer fluid temperature. The fluid temperatures used are $400 \mathrm{~K}, 500 \mathrm{~K}, 600 \mathrm{~K}$ and $650 \mathrm{~K}$. The porosity of the plate was fixed at 0.65 . The study shows that, for a given value of insert orientation, insert spacing and insert size, there is a range of Reynolds numbers for which the thermal performance of the receiver improves with the use of perforated plate inserts. In this range, the modified thermal efficiency increases between $1.2-8 \%$. The thermodynamic performance of the receiver due to inclusion of perforated plate inserts is shown to improve for flow rates lower than $0.01205 \mathrm{~m}^{3} / \mathrm{s}$. Receiver temperature gradients are shown to reduce with the use of inserts. Correlations for Nusselt number and friction factor were also derived and presented.
\end{abstract}

Keywords: Parabolic trough receiver, Perforated plate inserts, Temperature gradients, Thermal performance, Modified thermal efficiency, Thermodynamic performance

\footnotetext{
${ }^{\dagger}$ Corresponding author Tel.: +27 21 650-3673; fax: +27 21 650-3240

E-mail address: tunde.bello-ochende@uct.ac.za, , josua.meyer@up.ac.za
} 


\section{NOMENCLATURE}

\begin{tabular}{|c|c|}
\hline$A$ & Area, $\mathrm{m}^{2}$ \\
\hline$A_{a}$ & Collector's projected aperture area, $\mathrm{m}^{2}$ \\
\hline$a_{c}$ & Collector aperture width, $\mathrm{m}$ \\
\hline$A_{r}$ & Absorber tube's projected area, $\mathrm{m}^{2}$ \\
\hline$B e$ & Bejan number \\
\hline$C_{2 p}$ & Inertial resistance factor, $\mathrm{m}^{-1}$ \\
\hline$c_{p}$ & Specific heat capacity, $\mathrm{J} \mathrm{kg}^{-1} \mathrm{~K}^{-1}$ \\
\hline$C_{R}$ & Concentration ratio \\
\hline$d$ & Perforated plate diameter, $\mathrm{m}$ \\
\hline$d_{g i}$ & Glass cover inner diameter, $\mathrm{m}$ \\
\hline$d_{g o}$ & Glass cover outer diameter, $\mathrm{m}$ \\
\hline$d_{r i}$ & Absorber tube inner diameter, $\mathrm{m}$ \\
\hline$d_{r o}$ & Absorber tube outer diameter, $\mathrm{m}$ \\
\hline DNI & Direct normal irradiance, $\mathrm{W} / \mathrm{m}^{2}$ \\
\hline$f$ & Darcy friction factor \\
\hline$h$ & Heat transfer coefficient, $\mathrm{W} \mathrm{m}^{-2} \mathrm{~K}^{-1}$ \\
\hline$h_{w}$ & Glass cover outer heat transfer coefficient, $\mathrm{W} \mathrm{m}^{-2} \mathrm{~K}^{-1}$ \\
\hline$I_{b}$ & Direct solar radiation, $\mathrm{W} \mathrm{m}^{-2}$ \\
\hline$k$ & Turbulent kinetic energy per unit mass, $\mathrm{m}^{2} \mathrm{~s}^{-2}$ \\
\hline$L$ & Receiver length, $\mathrm{m}$ \\
\hline$\dot{m}$ & Mass flow rate, $\mathrm{kg} / \mathrm{s}$ \\
\hline $\mathrm{Nu}$ & Nusselt number \\
\hline$N_{s, e n}$ & Entropy generation ratio $=S_{g e n} /\left(S_{g e n}\right)_{o}$ \\
\hline$P$ & Pressure, $\mathrm{Pa}$ \\
\hline$p$ & Perforated plate spacing, $\mathrm{m}$ \\
\hline $\operatorname{Pr}$ & Prandtl number \\
\hline$q^{\prime \prime}$ & Heat flux, $\mathrm{W} \mathrm{m}^{-2}$ \\
\hline$\dot{Q}_{u}$ & Heat transfer rate $(\mathrm{W})$ \\
\hline$r$ & Radial position, $\mathrm{m}$ \\
\hline $\operatorname{Re}$ & Reynolds number \\
\hline$S_{\text {gen }}$ & Entropy generation rate due to heat transfer and fluid friction, $\mathrm{W} / \mathrm{K}$ \\
\hline$S_{\text {gen }}^{\prime}$ & Entropy generation rate per unit meter $(\mathrm{W} / \mathrm{mK})$ \\
\hline$S_{m}$ & Momentum source term \\
\hline$\left(S_{g e n}\right)_{H}$ & Entropy generation due to heat transfer, $\mathrm{W} / \mathrm{K}$ \\
\hline$\left(S_{g e n}\right)_{F}$ & Entropy generation due to fluid friction, $\mathrm{W} / \mathrm{K}$ \\
\hline$S^{\prime \prime \prime}$ gen & Volumetric entropy generation, $\mathrm{W} \mathrm{m} \mathrm{m}^{-3} \mathrm{~K}^{-1}$ \\
\hline$\left(S^{\prime \prime \prime \prime}{ }_{g e n}\right)_{F}$ & Volumetric entropy generation due to fluid friction, $\mathrm{W} \mathrm{m}^{-3} \mathrm{~K}^{-1}$ \\
\hline$\left(S^{\prime \prime \prime \prime} \operatorname{gen}_{H}\right)_{H}$ & Volumetric entropy generation due to heat transfer, $\mathrm{W} \mathrm{m}^{-3} \mathrm{~K}^{-1}$ \\
\hline$S^{\prime \prime \prime} P R O D, V D$ & Volumetric entropy production by direct dissipation, $\mathrm{W} \mathrm{m} \mathrm{m}^{-3} \mathrm{~K}^{-1}$ \\
\hline$S_{P R O D, T D}^{\prime \prime \prime}$ & Volumetric entropy production by turbulent dissipation, $\mathrm{W} \mathrm{m}^{-3} \mathrm{~K}^{-1}$ \\
\hline$S_{P R O D, T}^{\prime \prime \prime}$ & Volumetric entropy production by heat transfer with mean temperatures, $\mathrm{W} \mathrm{m}^{-3} \mathrm{~K}^{-1}$ \\
\hline$S_{P R O D, T G}$ & Volumetric entropy production by heat transfer with fluctuating temperatures, $\mathrm{W} \mathrm{m}^{-3} \mathrm{~K}^{-1}$ \\
\hline$T$ & Temperature, $\mathrm{K}$ \\
\hline$u, v, w$ & Velocity components, $\mathrm{m} \mathrm{s}^{-1}$ \\
\hline & Volume, $\mathrm{m}^{3}$ \\
\hline
\end{tabular}


$V_{w} \quad$ Wind velocity, $\mathrm{m} / \mathrm{s}$

$\dot{V} \quad$ Volume flow rate, $\mathrm{m}^{3} / \mathrm{s}$

$\dot{W}_{p} \quad$ Pumping power, $\mathrm{W}$

$u_{i}, u_{j} \quad$ Averaged velocity components, $\mathrm{m} \mathrm{s}^{-1}$

$u_{i}{ }^{\prime}, u_{j}{ }^{\prime} \quad$ Velocity fluctuations, $\mathrm{m} \mathrm{s}^{-1}$

$x_{i}, x_{j} \quad$ Spatial coordinates, $\mathrm{m}$

$x, y, z \quad$ Cartesian coordinates

$y^{+} \quad$ Dimensionless wall coordinate

$-\rho \overline{u_{i}^{\prime} u_{j}^{\prime}} \quad$ Reynolds stresses, $\mathrm{Nm}^{-2}$

$\nabla p \quad$ Pressure drop, $\mathrm{Pa}$

$\Delta m \quad$ Perforated plate thickness, $\mathrm{m}$

Greek letters

$\begin{array}{ll}\alpha & \text { Thermal diffusivity, } \mathrm{m}^{2} \mathrm{~s}^{-1} \\ \alpha_{a b s} & \text { Absorber tube absorptivity } \\ \alpha_{p} & \text { Permeability of the perforated plate, } \mathrm{m}^{2} \\ \alpha_{t} & \text { Turbulent thermal diffusivity, } \mathrm{m}^{2} \mathrm{~s}^{-1} \\ \sigma_{e} & \text { Slope error, mrad } \\ \sigma_{h . t} & \text { Turbulent Prandtl number for energy } \\ \beta & \text { Plate orientation angle, degrees } \\ \delta_{i j} & \text { Kronecker delta } \\ \varepsilon & \text { Turbulent dissipation rate, } \mathrm{m}^{2} \mathrm{~s}^{-3} \\ \xi & \text { Emissivity } \\ \phi & \text { Absorber tube temperature gradient, }{ }^{\circ} \mathrm{C} \\ \varphi_{r} & \text { Collector rim angle, degrees } \\ \rho & \text { Density, kg }{ }^{-3} \\ \rho & \text { Collector Reflectance } \\ \lambda & \text { Fluid thermal conductivity, } \mathrm{Wm}^{-1} \mathrm{~K}^{-1} \\ \eta_{t h, m} & \text { Modified thermal efficiency, } \% \\ \tau_{g} & \text { Glass cover transmissivity } \\ \tau_{w} & \text { Wall shear stress } \\ \theta & \text { Receiver angle, degrees } \\ \mu & \text { Viscosity, Pa s } \\ \mu_{t} & \text { Turbulent viscosity, Pa s } \\ \mu_{\tau} & \text { Friction velocity,m } / \mathrm{s} \\ \mu_{e f f} & \text { Effective viscosity, Pa s } \\ v & \text { Kinematic viscosity, } \mathrm{m}^{2} \mathrm{~s}^{-1} \\ \chi & \text { Thermal enhancement factor }=N u /(N u)_{\mathrm{o}} /\left(f / f_{o}\right)^{1 / 3}\end{array}$

Subscripts

$a m b \quad$ Ambient state

abs Absorber tube

abs, max Absorber tube maximum temperature

$b \quad$ Bulk fluid state

gi Inner glass cover wall

go outer glass cover wall 


$\begin{array}{ll}i, j, k & \text { General spatial indices } \\ \text { inlet } & \text { Absorber tube inlet } \\ \text { max } & \text { Maximum value } \\ o & \text { Reference case (plain absorber tube - no inserts) } \\ \text { outlet } & \text { absorber tube outlet } \\ r o & \text { Absorber tube outer wall } \\ r i & \text { Absorber tube inner wall } \\ s k y & \text { Sky temperature } \\ t & \text { Turbulent } \\ w & \text { Wall } \\ \text { Superscripts } \\ - & \text { Mean value } \\ \sim & \text { Dimensionless value } \\ \cdot & \text { Fluctuation from mean value }\end{array}$

\section{INTRODUCTION}

Parabolic trough solar collectors are one of the most technically and commercially developed technologies of the available concentrated solar power technologies [1,2]. The parabolic trough's linear receiver is a central component to the performance of the entire collector system. Its state and design greatly affects the performance of the entire collector system. The performance of the receiver is significantly affected by the thermal loss and heat transfer from the absorber tube to the working (heat transfer) fluid [3]. The conventional receiver consists of an evacuated glass envelope to minimize the convection heat loss and a selectively coated absorber tube to minimize the radiation heat loss [2]. Numerous studies have been carried out to characterize the thermal performance of the receiver and to determine the thermal loss at different receiver conditions [4-9]. From these studies, it has been shown that: the thermal loss is majorly dependent on the state of the annulus space between the glass cover and the absorber tube, the absorber tube selective coating, the temperature of the absorber tube, the wind speed and the heat transfer from the absorber tube to the heat transfer fluid.

With the availability of lightweight materials, the use of higher concentration ratios has become feasible [10]. Higher concentration ratios ensure shorter and less expensive collectors given the reduction in the number of drives and connections required. However, larger concentration ratios mean increased entropy generation rates [11], increased absorber tube circumferential temperature gradients as well higher peak temperatures.

The presence of circumferential temperature gradients in the receiver's absorber tube is a major concern. At low flow rates, higher temperature gradients existing in the tube's circumference can cause bending of the tube and eventual breakage of the glass cover $[12,13]$. And the peak temperature in the absorber tube 
facilitate degradation of the heat transfer fluid especially as these temperatures increase above $673.15 \mathrm{~K}$ $[14,15]$. The degradation of the heat transfer fluid results in hydrogen permeation in the receiver's annulus. With formation of hydrogen in the receiver's annulus, the receiver's thermal loss increases significantly thereby affecting the collector thermal performance [16].

Temperature gradients and temperature peaks in the receiver's absorber tube exist due to the non-uniform heat flux profile received on the absorber tube, with concentrated heat flux on the lower half of the absorber tube and nearly direct solar radiation on the upper half [17-20]. Most failures of parabolic trough receivers, especially the breakage of the glass cover have been attributed to the circumferential temperature gradients in the absorber tube $[2,13]$. Therefore, reducing these temperature gradients and temperature peaks can go a long way in increasing the life span of the receiver and avoiding the thermal loss due to vacuum loss and hydrogen permeation in receiver's annulus space. The maximum temperature gradient for safe operation of receiver tubes is about $50 \mathrm{~K}$ [21]

Enhancement of convective heat transfer in the receiver's absorber tube is one of the relevant solutions to the above concerns. With improved convective heat transfer in the absorber tube, circumferential temperature gradients and peak temperatures in the absorber tube can be reduced and risks of breakage and hydrogen formation can be minimised. As such, heat transfer enhancement in the receiver's absorber tube has received considerable attention in the recent past. Reddy et al. [22] numerically analyzed a receiver with various porous fin geometries and compared its performance with a receiver having longitudinal fins. Kumar and Reddy [3] investigated the performance of the receiver with a porous disc at different angles of orientation, different heights and different distances between the consecutive discs. Muñoz and Abánades [13] analyzed an internally helically finned absorber tube with a view of improving thermal performance and minimizing the temperature gradients in the absorber tube. Absorber tube temperature difference was reduced by between $15.3-40.9 \%$. All these studies used an approximate heat flux boundary condition on the receiver's absorber tube. The use of realistic non-uniform heat flux boundary condition is crucial in determining the temperature gradients, peak temperatures as well as entropy generation rates in the receiver.

Recently Cheng et al. [23] analyzed the heat transfer enhancement of a parabolic trough receiver using unilateral longitudinal vortex generators with a realistic non-uniform heat flux boundary condition. The wall temperatures and thermal loss were found to decrease with each geometrical parameter considered. Wang et al.[21] investigated heat transfer enhancement using metal foams in a parabolic trough receiver for direct steam generation using realistic non-uniform heat flux boundary condition. They showed a maximum circumferential temperature difference was shown to reduce by $45 \%$. 
Several other studies have been carried out on heat transfer enhancement for various applications using different techniques as reviewed by Manglik [24,25]. Studies on heat transfer enhancement in parabolic trough receivers with realistic non-uniform heat flux boundary conditions are not wide spread. Moreover, most studies on heat transfer enhancement have only focused on heat transfer and fluid friction performance. Investigations of the effect of heat transfer enhancement on thermodynamic performance of enhanced devices are still few. Therefore, in this paper, a numerical investigation of heat transfer, fluid friction and thermodynamic performance of a receiver with a centrally placed perforated plate is carried out. The plate is centrally placed to provide heat transfer enhancement in the core flow thereby avoiding any possible hot spots that can facilitate degradation of the heat transfer fluid [14] which are characteristic of heat transfer enhancement methods with recirculation, separation and re-attachment. In addition to heat transfer performance, using the entropy generation minimization method [26], the effect of heat transfer enhancement on the thermodynamic performance of the receiver is also investigated and presented. To the author's best knowledge, the use of centrally placed perforated plate inserts for heat transfer enhancement in a parabolic trough receiver has not been studied previously.

\section{PHYSICAL MODEL}

The perforated plate assembly is considered to be supported on a thin axially placed rod as shown in Fig. 1(a). The placement of the perforated plate defined by spacing between the two consecutive plates $(p)$, the diameter of the plate $(d)$ and the angle of orientation measured from the positive $y$-axis $(\beta)$. $\beta$ is negative in the clockwise direction and positive in the anti-clockwise direction. In our analysis, we have considered a simplified model of the parabolic trough receiver in which the effect of the central rod and other supports is considered negligible. Further still, the flow was found to be periodically fully developed after about five perforated plate inserts regardless of the spacing. Therefore, for our analysis a periodic module of the receiver's absorber tube was considered as shown in Fig. 1(c).

Similar to actual receivers, the space between the absorber tube and the glass cover is considered evacuated to very low vacuum pressures $(0.013 \mathrm{~Pa})$ [2] such that only radiation heat loss takes place. The receiver tube used is similar to SEGS LS-2 receiver [7]. The receiver parameters used are shown in Table 1. Due to the symmetrical nature of the model, only half of the receiver tube was considered in our analysis. The parameters used in this study for the reflector, receiver and perforated plate inserts are given in Table 1. 
Table 1. Geometrical and optical values of the parabolic trough collector

\begin{tabular}{cccccc}
\hline & Reflector & \multicolumn{2}{c}{ Receiver } & \multicolumn{2}{c}{ Perforated plate } \\
\hline$a_{c}$ & $6.0 \mathrm{~m}$ & $d_{r i}$ & $0.066 \mathrm{~m}$ & $-30^{\circ}$ to $30^{\circ}$ & $0.03-0.06 \mathrm{~m}$ \\
$L_{c}$ & $7.8 \mathrm{~m}$ & $d_{r o}$ & $0.07 \mathrm{~m}$ & $d$ & $0.04-0.20 \mathrm{~m}$ \\
$\rho$ & 0.96 & $\tau_{g}$ & 0.97 & 0.96 & \\
$\sigma_{e}$ & $0.0002 \mathrm{mrad}$ & $\alpha_{a b s}$ & & \\
\hline
\end{tabular}

(a)

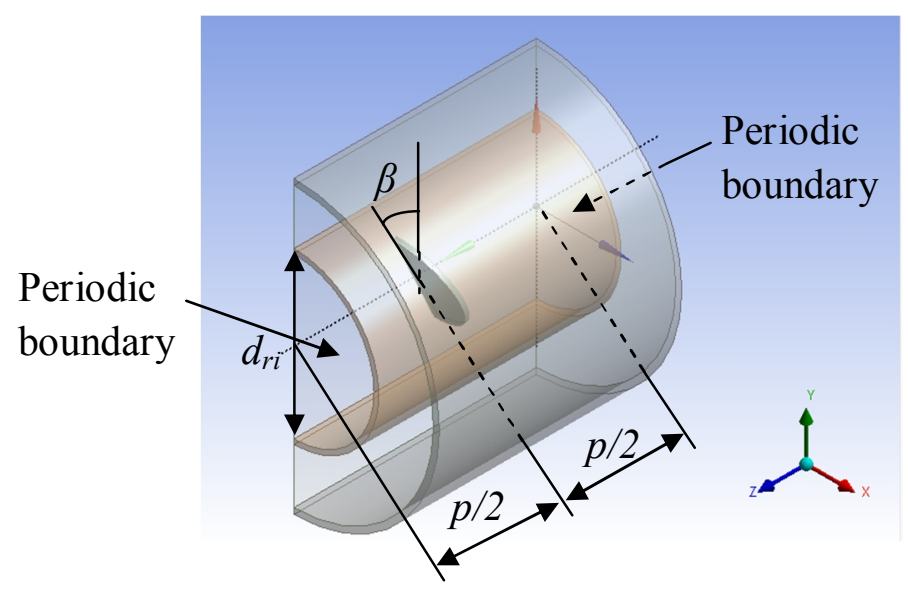

(b)

(c)

Fig. 1. (a) Longitudinal section of the receiver with perforated plate inserts (b) Cross-section of the receiver tube with perforated plate inserts (c) Periodic computational domain 


\section{NUMERICAL ANALYSIS}

\subsection{Governing equations}

For the range of Reynolds numbers considered, the flow is in the fully developed turbulent regime. As such, the governing equations used in our analysis for steady-state and three-dimensional turbulent flow are the continuity, momentum and energy equations given by;

Continuity

$\frac{\partial\left(\rho u_{i}\right)}{\partial x_{i}}=0$

Momentum equation

$\frac{\partial}{\partial x_{j}}\left(\rho u_{i} u_{j}\right)=-\frac{\partial P}{\partial x_{i}}+\frac{\partial}{\partial x_{j}}\left[\mu_{e f f}\left(\frac{\partial u_{i}}{\partial x_{j}}+\frac{\partial u_{j}}{\partial x_{i}}\right)-\frac{2}{3} \mu_{e f f} \frac{\partial u_{i}}{\partial x_{i}} \delta_{i j}-\rho \overline{u_{i}^{\prime} u_{j}^{\prime}}\right]+S_{m}$

Energy equation

$\frac{\partial}{\partial x_{j}}\left(\rho u_{j} c_{p} T\right)=\frac{\partial}{\partial x_{j}}\left(\lambda \frac{\partial T}{\partial x_{j}}+\frac{\mu_{t}}{\sigma_{h, t}} \frac{\partial\left(c_{P} T\right)}{\partial x_{j}}\right)+u_{j} \frac{\partial P}{\partial x_{j}}+\left[\mu_{e f f}\left(\frac{\partial u_{i}}{\partial x_{j}}+\frac{\partial u_{j}}{\partial x_{i}}\right)-\frac{2}{3} \mu_{e f f} \frac{\partial u_{i}}{\partial x_{i}} \delta_{i j}-\rho \overline{u_{i}^{\prime} u_{j}^{\prime}}\right] \frac{\partial u_{i}}{\partial x_{j}}$

The additional terms appearing in Eqs. (1) - (3) represent the turbulence effects and the Reynolds stresses $-\rho \overline{u_{i}^{\prime} u_{j}^{\prime}} . \quad u_{i}, u_{j}$ are the time-averaged velocity components in the $i$ - and $j$-directions respectively and $T$ the time-averaged temperature. The effective viscosity is given by $\mu_{e f f}=\mu+\mu_{t}$ and $\lambda$ is the fluid thermal conductivity. The most common approach for representation of Reynolds stresses is the Boussinesq approach, where the Reynolds stresses are related to the mean velocity gradients through [27]

$-\rho \overline{u_{i}^{\prime} u_{j}^{\prime}}=\mu_{t}\left(\frac{\partial u_{i}}{\partial x_{j}}+\frac{\partial u_{j}}{\partial x_{i}}\right)-\frac{2}{3}\left(\rho k+\mu_{t} \frac{\partial u_{k}}{\partial x_{k}}\right) \delta_{i j}$

Where $k$ is the turbulent kinetic energy per unit mass given by

$k=\frac{1}{2}\left(\overline{u^{\prime 2}}+\overline{v^{\prime 2}}+\overline{w^{\prime 2}}\right)$

This approach has a relatively lower computation cost compared to the Reynolds stress transport model approach which solves transport equations for each of the terms in the Reynolds stress tensor. A number of turbulence models based on the Boussinesq approach have been developed to solve the closure problem resulting from the averaging process of the Navier-Stokes equations. The $k-\varepsilon$ models are the widely used and validated models for most flows present in engineering applications [27,28]. For this study the realizable $k-\varepsilon$ model which is an improvement of the standard $k-\varepsilon$ was adopted [27,29]. The $k-\varepsilon$ model solves two additional 
equations for the transport of turbulent kinetic energy and turbulent dissipation rates. The detailed description of the realizable $k-\varepsilon$ model is presented in ref.[27].

The source term $\left(S_{m}\right)$ added to the momentum equation in Eq. (2) represents the pressure drop across the perforated plate. The perforated plate is modeled as porous media of finite thickness with directional permeability over which there is a pressure drop. The pressure drop is defined accordingly as a sum of the viscous term according to Darcy's law and an inertial loss term [30] as:

$\nabla P-\left(\frac{\mu}{\alpha_{p}} u_{i}+€_{2 p} \frac{1}{2} \rho|u| u_{i}\right) \Delta m$

Where $\alpha_{p}$ is the permeability of the porous medium, $C_{2 p}$ is the inertial resistance factor, $\Delta m$ is the thickness of the porous media. For perforated plates, it has been shown that the first term is negligible such that only the inertial loss term should be considered [30,31]. The coefficient $C_{2 p}$ has been determined from data presented by Weber et al. [32] for perforated plates and flat bar screens. In the stream wise direction $C_{2 p}=853 \mathrm{~m}^{-1}$ for the considered porosity of 0.65 , and plate thickness of $0.0015 \mathrm{~m}$, in the other directions inertial resistance factors of much higher magnitudes are specified to restrict flow in those directions.

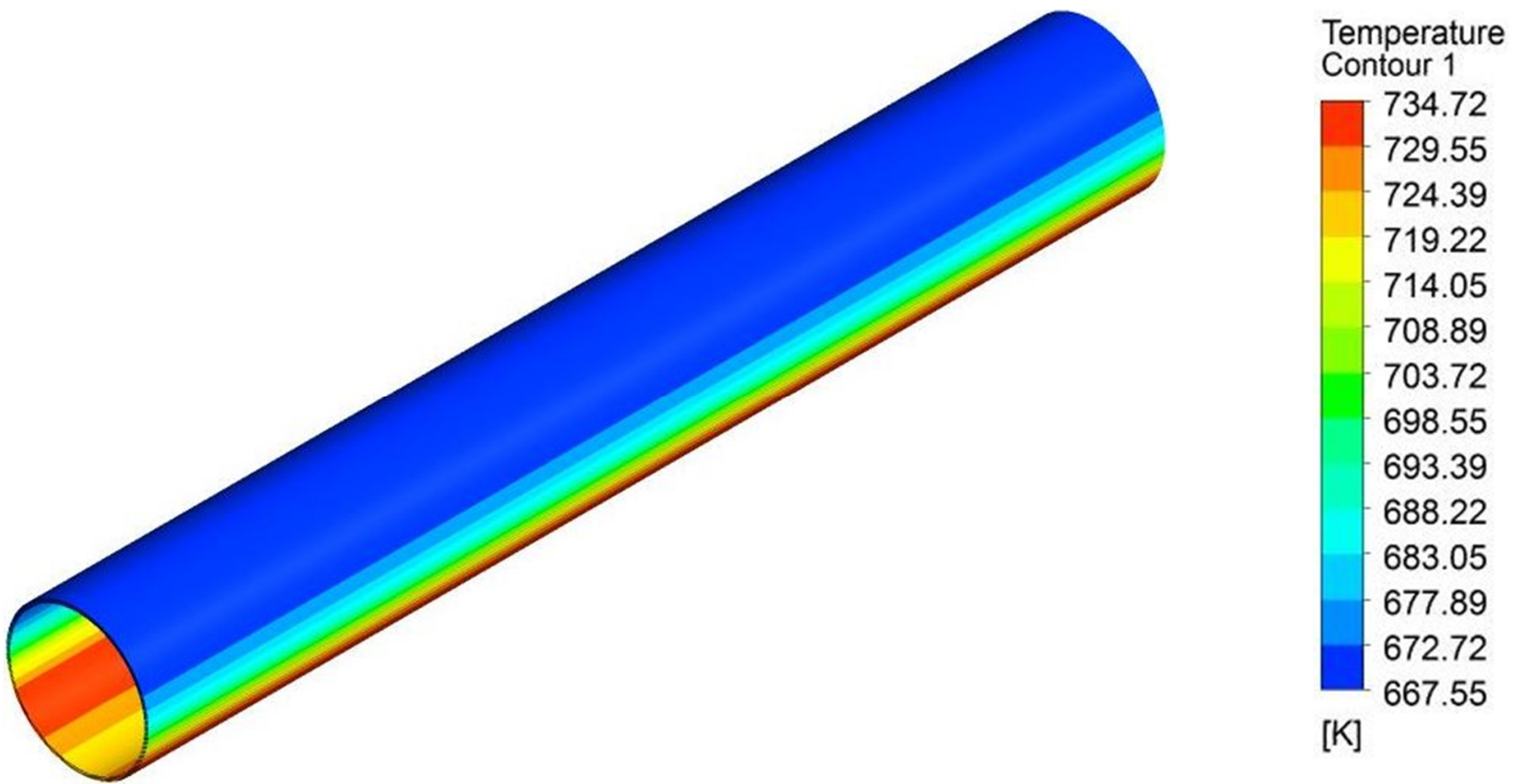

(b)

Fig. 2. (a) Heat flux distribution on the absorber tube's circumference (b) Contours of temperature on the absorber tube for $T_{\text {inlet }}=$ $650 \mathrm{~K}$ and $R e=202,420$ at $C_{R}=86$ and rim angle of $80^{\circ}$ 


\subsection{Boundary conditions}

The boundary conditions used in this study are: (1) The outer wall of the absorber tube receives a nonuniform heat flux. The lower half receives almost concentrated solar radiation while the upper half receives direct solar radiation. The heat flux distribution used in this study is shown in Fig. 2 (a) as determined using ray tracing in SolTrace [33]. For this study, the rim angle $\left(\varphi_{r}\right)$ used was $80^{\circ}$ and the aperture width was $6 \mathrm{~m}$ giving a concentration ratio of 86 . The resulting temperature distribution on the receiver's absorber tube is as shown in Fig. 2(b). The receiver angle $\theta$, is the receiver's circumferential angle as shown in Fig. 1(b). A Direct normal irradiance (DNI) of $1000 \mathrm{~W} / \mathrm{m}^{2}$ was used. (2) Periodic boundary conditions are used for the absorber tube's inlet and outlet. (3) The inner absorber tube walls are considered no-slip and no-penetration. (4) For the inlet and outlet of the receiver's annulus space, symmetry boundary condition is used such that the normal gradients of all flow variables are zero. (5) For the outer glass cover, a mixed boundary condition is used to account for both radiation and convection heat transfer. For radiation from the receiver, the receiver exchanges heat by radiation with the larger enclosure, the sky. The sky temperature is determined as a function of the ambient temperature from [34]:

$$
T_{\text {sky }}=0.0552 T_{a m b}^{1.5}
$$

The ambient temperature used is $300 \mathrm{~K}$. The convection heat transfer coefficient used for the convection boundary condition is given by [35]:

$$
h_{w}=V_{w}^{0.58} d_{g o}^{-0.42}
$$

Where $V_{w}$ is the wind speed, taken as $2 \mathrm{~m} / \mathrm{s}$ in this study and $d_{g o}$ is the glass cover outer diameter.

On the symmetry plane, the normal velocity and the normal gradients of all flow variables are zero.

In this study, the concentration ratio, $C_{R}$ is defined as $C_{R}=A_{a} / A_{r}$, where $A_{a}$ is the projected area of the collector's aperture and $A_{r}$ is the projected area of the absorber tube.

\subsection{Entropy generation}

For evaluation of thermodynamic performance of the enhanced receiver, the entropy generation minimization method is used. Based on the entropy generation minimization method, a configuration that has less entropy generation rates is considered to have better thermodynamic performance. For such a configuration, the destruction of available work or exergy loss is less when compared with a configuration with higher entropy generation rates [26]. As such, the entropy generation minimization method has been used by several researchers for optimization of thermodynamic systems [36,37] while others have applied it to analysis heat transfer problems [38-40]. In heat transfer enhancement, the entropy generation in the 
enhanced device should be lower than entropy generation in a non-enhanced device for better thermodynamic performance [26].

The entropy generation rate per unit volume is determined as a sum of the heat transfer irreversibility and fluid friction irreversibility from the following relations [38]:

$S_{g e n}^{\prime \prime \prime}=\left(S_{g e n}^{\prime \prime \prime}\right)_{F}+\left(S_{g e n}^{\prime \prime \prime}\right)_{H}$

The entropy generation per unit volume due to fluid friction irreversibility $\left(S_{g e n}^{\prime \prime \prime}\right)_{F}$ is given by

$\left(S_{g e n}^{\prime \prime \prime}\right)_{F}=S_{P R O D, V D}^{\prime \prime \prime}+S_{P R O D, T D}^{\prime \prime \prime}$

Where $S_{P R O D, V D}^{\prime \prime \prime}$, is the term representing entropy production by direct dissipation given by

$$
S_{P R O D, V D}^{\prime \prime \prime}=\frac{\mu}{T}\left(\frac{\partial u_{i}}{\partial x_{j}}+\frac{\partial u_{j}}{\partial x_{i}}\right) \frac{\partial u_{i}}{\partial x_{j}}
$$

And $S_{P R O D, T D}^{\prime \prime \prime}$ represents entropy production by indirect or turbulent dissipation and is given by

$S_{P R O D, T D}^{\prime \prime \prime}=\frac{\rho \varepsilon}{T}$

The entropy generation per unit volume due to heat transfer irreversibility is given by

$\left(S_{g e n}^{\prime \prime \prime}\right)_{H}=S_{P R O D, T}^{\prime \prime \prime}+S_{P R O D, T G}^{\prime \prime \prime}$

where $S_{P R O D, T}^{\prime \prime \prime}$ is the entropy production by heat transfer with mean temperatures given by

$S_{P R O D, T}^{\prime \prime \prime}=\frac{\lambda}{T^{2}}(\nabla T)^{2}$

And $S_{P R O D, T G}^{\prime \prime \prime}$ is the entropy production by heat transfer with fluctuating temperatures given by

$S_{P R O D, T G}^{\prime \prime \prime}=\frac{\alpha_{t}}{\alpha} \frac{\lambda}{T^{2}}(\nabla T)^{2}$

In Eq. (15), $\alpha$ and $\alpha_{t}$ are the viscous and turbulent thermal diffusivities respectively. The velocities and temperatures in Eqs. (9) - (15) are time-averaged quantities.

For a fluid element of volume $\mathrm{V}$, the total entropy generation rate is obtained as the volume integral of the entropy generation rate per unit volume according to:

$S_{g e n}=\iiint_{V} S_{g e n}^{\prime \prime \prime} d V$ 


\section{SOLUTION PROCEDURE AND DATA REDUCTION}

\subsection{Solution procedure}

The numerical solution was implemented using a commercial software package ANSYS® 14 . The governing equations together with the boundary conditions were solved using a finite-volume approach implemented in a computational fluid dynamics code ANSYS FLUENT [30]. The computational domain was discretized using tetrahedral elements with a structured mesh in the absorber tube wall normal direction and as structured mesh in the receiver's annulus space. The coupling of pressure and velocity and was done with the SIMPLE algorithm [41]. Second-order upwind schemes were employed for integrating the governing equations together with the boundary conditions over the computational domain. To capture the high resolution of gradients in the near wall regions, the $y^{+}$value of about 1 was ensured for all simulations. The enhanced wall treatment method was used for modeling the near-wall phenomena for such low values of $y^{+}$. Where $y^{+}=y \mu_{\tau} / v, v$ is the fluid's kinematic viscosity, $y$ is the distance from the wall, and $u_{\tau}$ is the friction velocity given by $\mu_{\tau}=\sqrt{\left(\tau_{w} / \rho\right)}$. For accurate prediction of entropy generation rates, the solution was considered converged when the scaled residuals of continuity, momentum, turbulence kinetic energy, turbulent dissipation rate and energy ceased changing after about 100 successive iterations. The values of the scaled residuals after these iterations were in the order of less than $10^{-4}$ for the continuity equation, less than $10^{-6}$ for velocity, turbulent kinetic energy and turbulent dissipation rate and less than $10^{-7}$ for energy. The discrete ordinates model was used for modeling radiation between the absorber tube's outer wall and the glass cover's inner wall, with air in the annulus space taken to radiatively non-participating.

The heat transfer fluid used in the numerical analysis is SYLTHERM 800 [42]. Its thermo-physical properties are temperature dependent as shown in product's technical data [42]. Fluid temperatures in parabolic trough receivers range from $100{ }^{\circ} \mathrm{C}(373.15)$ to $400{ }^{\circ} \mathrm{C}(673.15 \mathrm{~K})$ depending on whether it is for low or high temperature application [43,44]. In this study, we used inlet temperatures of $400 \mathrm{~K}, 500 \mathrm{~K}, 600 \mathrm{~K}$ and $650 \mathrm{~K}$ to cover the low temperature applications range as well as high temperature applications. The heat transfer fluid properties at the considered temperatures are shown in Table 2. Stainless steel $(321 \mathrm{H})$ was used as the absorber tube material and glass cover made out of Pyrex ${ }^{\circledR}$ was used [16]. The absorber tube is

selectively coated, the coating emissivity varies with the temperature according to $\xi=0.000327(T+273.15)$ 0.065971 [16]. Where $T$ is the absorber tube temperature in ${ }^{\circ} \mathrm{C}$. 
Table 2. Heat transfer fluid properties [42]

\begin{tabular}{lcccc}
\hline & $T=400 \mathrm{~K}$ & $T=500 \mathrm{~K}$ & $T=600 \mathrm{~K}$ & $T=650 \mathrm{~K}$ \\
\hline Density $\left(\mathrm{kg} / \mathrm{m}^{3}\right)$ & 840 & 746 & 638 & 578 \\
Viscosity $(\mathrm{Pa} \mathrm{s})$ & 0.002164 & 0.000816 & 0.000386 & 0.000283 \\
Thermal conductivity $(\mathrm{W} / \mathrm{m} \mathrm{K})$ & 0.1148 & 0.0958 & 0.0770 & 0.0678 \\
Specific heat capacity $(\mathrm{J} / \mathrm{kg} \mathrm{K})$ & 1791.64 & 1964.47 & 2135.30 & 2218.65 \\
\hline
\end{tabular}

Grid dependence tests were carried out for representative cases of perforated plate arrangements at all Reynolds numbers considered in the study. The solution was considered grid independent when the maximum change of the entropy generation rate, Nusselt number and friction factor was less than $1 \%$ as the mesh element size was changed. The sample results of the grid dependence tests are shown in Table 3. The

Table 3: Mesh dependence studies

\begin{tabular}{ccccccc}
\hline Mesh Elements & $f$ & $N u$ & $S_{\text {gen }} /\left(S_{\text {gen }}\right)_{o}$ & $\Delta f$ & $\Delta N u$ & $\Delta S_{\text {gen }}$ \\
\hline (a) $\boldsymbol{R} \boldsymbol{e}=\mathbf{1 . 0 2} \times \mathbf{1 0}^{\mathbf{4}}, \tilde{p}=\mathbf{0 . 0 9}, \tilde{d}=\mathbf{0 . 7 6}$ and $\tilde{\beta}=\mathbf{- 1}$ & & & & \\
55,635 & 0.38248 & 225.80 & 0.6855 & & & \\
90,863 & 0.38203 & 217.69 & 0.7515 & 0.001 & -0.037 & 0.088 \\
154,925 & 0.38190 & 217.75 & 0.7493 & 0.000 & 0.000 & -0.003 \\
(b) $\boldsymbol{R} \boldsymbol{e}=\mathbf{1 . 9 4} \times \mathbf{1 0}^{\mathbf{4}}, \tilde{p}=\mathbf{0 . 1 8}, \tilde{d}=\mathbf{0 . 9 1}$ and $\tilde{\beta}=\mathbf{0}$ & & & & \\
83,557 & 0.40787 & 305.64 & 0.9236 & & & \\
141,617 & 0.40802 & 312.96 & 0.8624 & 0.000 & 0.023 & -0.07 \\
200,900 & 0.40851 & 314.00 & 0.8580 & 0.001 & 0.003 & -0.005 \\
350,855 & 0.40915 & 315.16 & 0.8577 & 0.002 & 0.004 & -0.000 \\
\hline
\end{tabular}

changes in friction factor, Nusselt number and entropy generation as the mesh size was changed are given by

$$
\Delta f \quad\left|\frac{\left(f^{i}-f^{i+1}\right)}{f^{i+1}}\right| \leq 0.01, \Delta N u=\left|\frac{\left(N u^{i}-N u^{i+1}\right)}{N u^{i+1}}\right| \leq 0.01 \text { and } \Delta S_{g e n}=\left|\frac{\left(N_{s, e n}^{i}-N_{s, e n}{ }^{i+1}\right)}{N_{s, e n}^{i+1}}\right| \leq 0.01 .
$$

Where $N_{s, e n}=S_{g e n} /\left(S_{g e n}\right)_{o}$

In Eq. (17), the indices $i$ and $i+1$ indicate the mesh before and after refinement respectively. Sample mesh used in this study is shown in Fig.3 


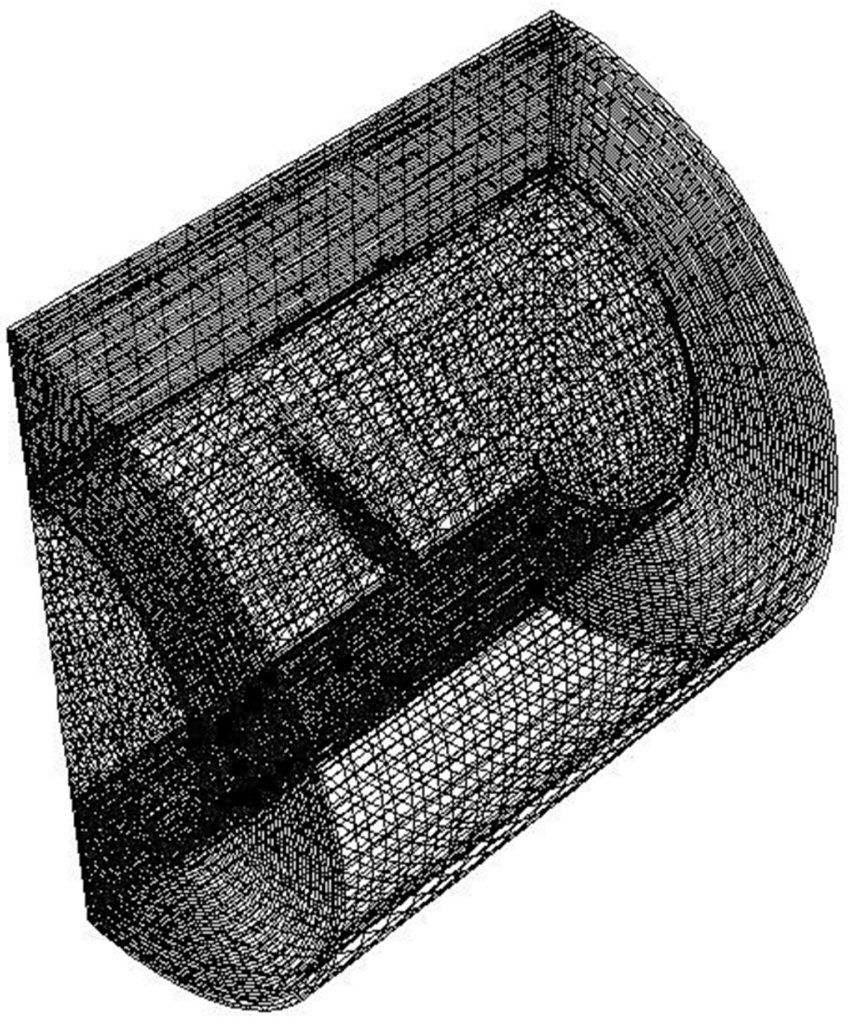

(a) Lateral view

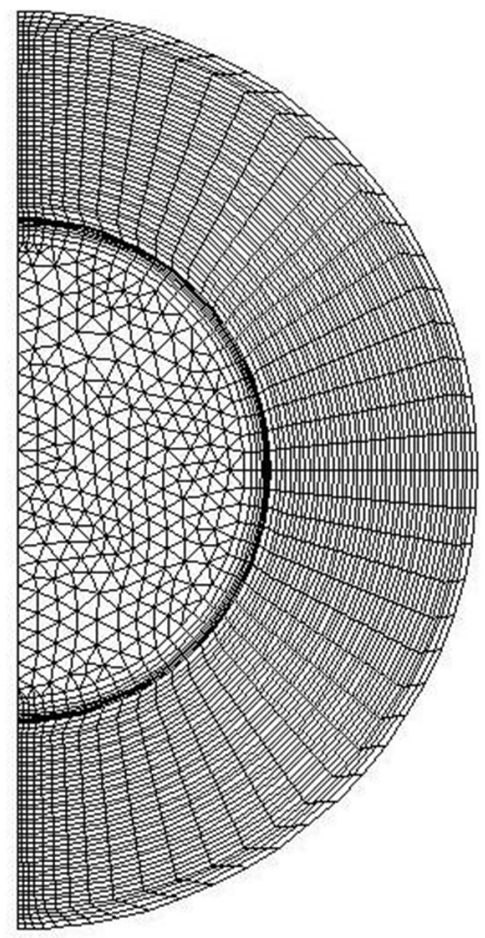

(b) Cross-Section view

Fig. 3. Sample mesh

\subsection{Data processing and analysis}

From Fig. 1 the following non-dimensional variables are defined:

$\tilde{p}=p / L ; \tilde{\beta} \quad \beta / \beta_{\max } ; \tilde{d} \quad \notin / d_{r i}$

Where $L$ is $1 \mathrm{~m}$ and $\beta_{\max }$ is $30^{\circ}, \tilde{p}$ is the dimensionless plate spacing, $\tilde{\beta}$ is the dimensionless plate orientation angle and $\tilde{d}$ is the dimensionless plate/insert size.

The results from our simulations are presented using the following parameters:

The average heat transfer coefficient is given by

$h=q^{\prime \prime} /\left(T_{r i}-T_{b}\right)$

Where $q^{\prime \prime}$ is the average heat flux on absorber tube's inner wall, $T_{r i}$ is the average inner wall temperature of the absorber tube and $T_{b}$ represents the bulk temperature of the fluid at the periodic boundaries The average Nusselt number is given by 
$N u=h d_{r i} / \lambda$

In which, $\lambda$ is the thermal conductivity of the heat transfer fluid.

The Reynolds number of flow for both the enhanced absorber tube and non-enhanced absorber tube is defined as

$R e=u_{\text {inlet }} d_{r i} / v$

In which, $u_{\text {inlet }}$ is the velocity at the periodic boundaries determined from $\dot{m}=\rho u_{\text {inlet }} A$, with A the crosssection area of absorber tube based on the inner diameter $d_{r i} . v$ is the kinematic coefficient of viscosity of the heat transfer fluid.

The Darcy-Weisbach friction factor is defined as

$f=\frac{\Delta P}{\frac{1}{2} \rho \cdot u_{\text {inlet }}^{2} \cdot \frac{L}{d_{\text {ri }}}}$

For smooth tubes, the Darcy-Weisbach friction factor $(f)$ is given by Petukhov's correlation [45] as

$f=(0.790 \ln R e-1.64)^{-2}$

Whereas the average Nusselt number for smooth tubes is given by the Gnielinski's correlation [45] for both low and high Reynolds numbers as

$$
N u=\frac{(f / 8)(R e-1000) P r}{1+12.7(f / 8)^{0.5}\left(\operatorname{Pr}^{2 / 3}-1\right)}
$$

For $0.5 \leq \operatorname{Pr} \leq 2000$ and $3 \times 10^{3} \leq \operatorname{Re} \leq 5 \times 10^{6}$

For a receiver with no inserts, our results were compared with the correlations given in Eqs. (23) and (24) as discussed in section 5.1.

\section{RESULTS AND DISCUSSIONS}

\subsection{Validation of numerical results}

Our numerical analysis was validated in several steps. For a receiver with a plain absorber tube, we have compared our results with experimental data from Dudley et al. [7] for receiver's temperature gain and collector efficiency to ensure that our receiver model is accurate. Table 4 shows the comparison of the present study receiver's temperature gain and collector efficiency with Dudley et al. [7] experimental data for a receiver $7.8 \mathrm{~m}$ long, $66 \mathrm{~mm}$ absorber tube internal diameter, $70 \mathrm{~mm}$ absorber tube external diameter and 
glass cover inner diameter of $115 \mathrm{~mm}$. Both the efficiency and temperature gain are within $8 \%$ of the experimental values. The heat transfer and fluid friction performance of the receiver with no inserts were

Table 4: Heat gain and collector efficiency validation (Dudley et al. [7])

\begin{tabular}{|c|c|c|c|c|c|c|c|c|c|c|c|}
\hline & $\begin{array}{c}\mathrm{DNI} \\
\left(\mathrm{W} / \mathrm{m}^{2}\right)\end{array}$ & $\begin{array}{l}\text { Wind } \\
\text { speed } \\
(\mathrm{m} / \mathrm{s})\end{array}$ & $\begin{array}{c}\text { Air } \\
\text { temperature } \\
\left({ }^{\circ} \mathrm{C}\right)\end{array}$ & $\begin{array}{l}\text { Flow rate } \\
(\mathrm{L} / \mathrm{min})\end{array}$ & $\begin{array}{l}T_{\text {inlet }} \\
\left({ }^{\circ} \mathrm{C}\right)\end{array}$ & $\begin{array}{c}\Delta T\left({ }^{\circ} \mathrm{C}\right) \\
\text { (Experimental) }\end{array}$ & $\begin{array}{l}\Delta T\left({ }^{\circ} \mathrm{C}\right) \\
\text { (Present } \\
\text { study) }\end{array}$ & $\begin{array}{c}\% \\
\text { error } \\
\Delta \mathrm{T}\end{array}$ & $\begin{array}{c}\text { Efficiency } \\
\text { (Experimental } \\
\text { ) }\end{array}$ & $\begin{array}{c}\text { Efficienc } \\
y \\
\text { (present } \\
\text { study) }\end{array}$ & $\begin{array}{c}\% \\
\text { error }\end{array}$ \\
\hline 1 & 933.7 & 2.6 & 21.2 & 47.70 & 102.2 & 21.80 & 22.11 & 1.42 & 72.51 & 72.78 & 0.37 \\
\hline 2 & 968.2 & 3.7 & 22.4 & 47.78 & 151.0 & 22.02 & 22.30 & 1.27 & 70.90 & 72.11 & 1.70 \\
\hline 3 & 982.3 & 2.5 & 24.3 & 49.10 & 197.5 & 21.26 & 22.00 & 3.48 & 70.17 & 70.61 & 0.63 \\
\hline 4 & 909.5 & 3.3 & 26.2 & 54.70 & 250.7 & 18.70 & 18.90 & 1.07 & 70.25 & 68.20 & -2.91 \\
\hline 5 & 937.9 & 1 & 28.8 & 55.50 & 297.8 & 19.10 & 17.71 & -7.28 & 67.98 & 62.65 & -7.85 \\
\hline 6 & 880.6 & 2.9 & 27.5 & 55.60 & 299.0 & 18.20 & 16.95 & -6.86 & 68.92 & 64.50 & -6.41 \\
\hline 7 & 920.9 & 2.6 & 29.5 & 56.80 & 379.5 & 18.10 & 17.39 & -3.92 & 62.34 & 58.48 & -6.19 \\
\hline 8 & 903.2 & 4.2 & 31.1 & 56.30 & 355.9 & 18.50 & 17.22 & -6.92 & 63.83 & 59.60 & -6.63 \\
\hline
\end{tabular}

validated using the Gnielinski correlation in Eq. (24) for Nusselt number and Petukhov's correlation given in Eq. (23) for friction factor. Good agreement was achieved as shown in the scatter plot in Fig. 4. Nusselt numbers are within $\pm 7 \%$ and friction factors are within $5.5 \%$.

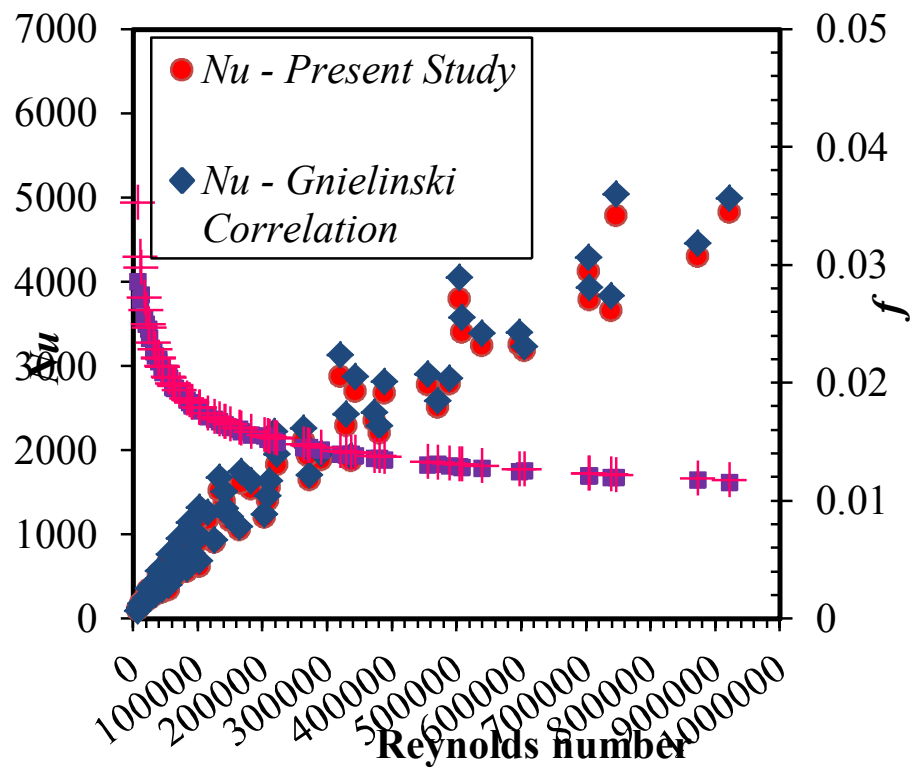

Fig. 4. Validation of plain receiver tube heat transfer and fluid friction performance 
From the present work, the Nusselt number for the receiver with a plain absorber tube is given by

$$
N u=0.0104 \operatorname{Pr}^{0.374} \operatorname{Re}^{0.885}
$$

$R^{2}=1.0$ for this correlation and the correlation predicts the Nusselt number within $\pm 4 \%$.

The friction factor correlation is

$$
f=0.173 \mathrm{Re}^{-0.1974}
$$

$R^{2}=0.994$ for the friction factor correlation and the correlation is valid within $\pm 3.5 \%$

Eqs. (25) - (26) were obtained with parameters in the range

$$
\begin{aligned}
& 1.02 \times 10^{4} \leq \operatorname{Re} \leq 7.38 \times 10^{5} \\
& 9.29 \leq \operatorname{Pr} \leq 33.7 \\
& 400 \mathrm{~K} \leq \mathrm{T} \leq 650 \mathrm{~K}
\end{aligned}
$$

The entropy generation model was validated by Bejan's analytical correlation [26] for heat transfer and fluid flow in a tube subject to a constant heat flux. Good agreement was achieved as shown in Fig. 5.

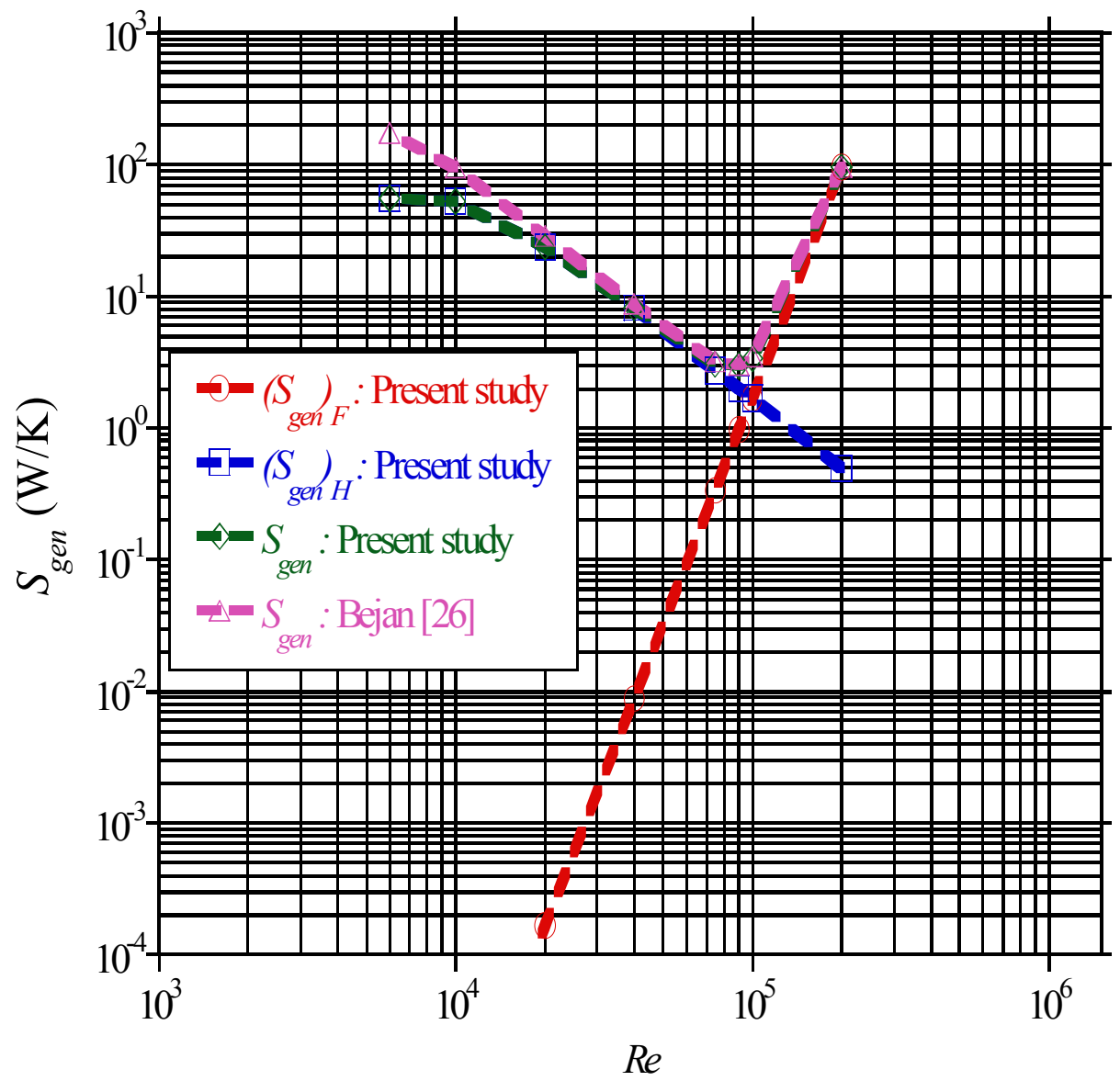

Fig. 5. Validation of the entropy generation model 
In computational fluid dynamics, perforated plates are essentially modeled as porous media with negligible viscous resistance [30]. Therefore, our work was further validated using data from Kumar and Reddy [3] for a receiver with a porous disc after which the viscous resistance terms were neglected for further analysis of our perforated plate model. Good agreement was obtained for both Nusselt numbers and friction factors for a porous disc at an angle of $30^{\circ}$ as shown in Table 5 .

Table 5: Validation of the perforated plate model with Ravi Kumar and Reddy [3]

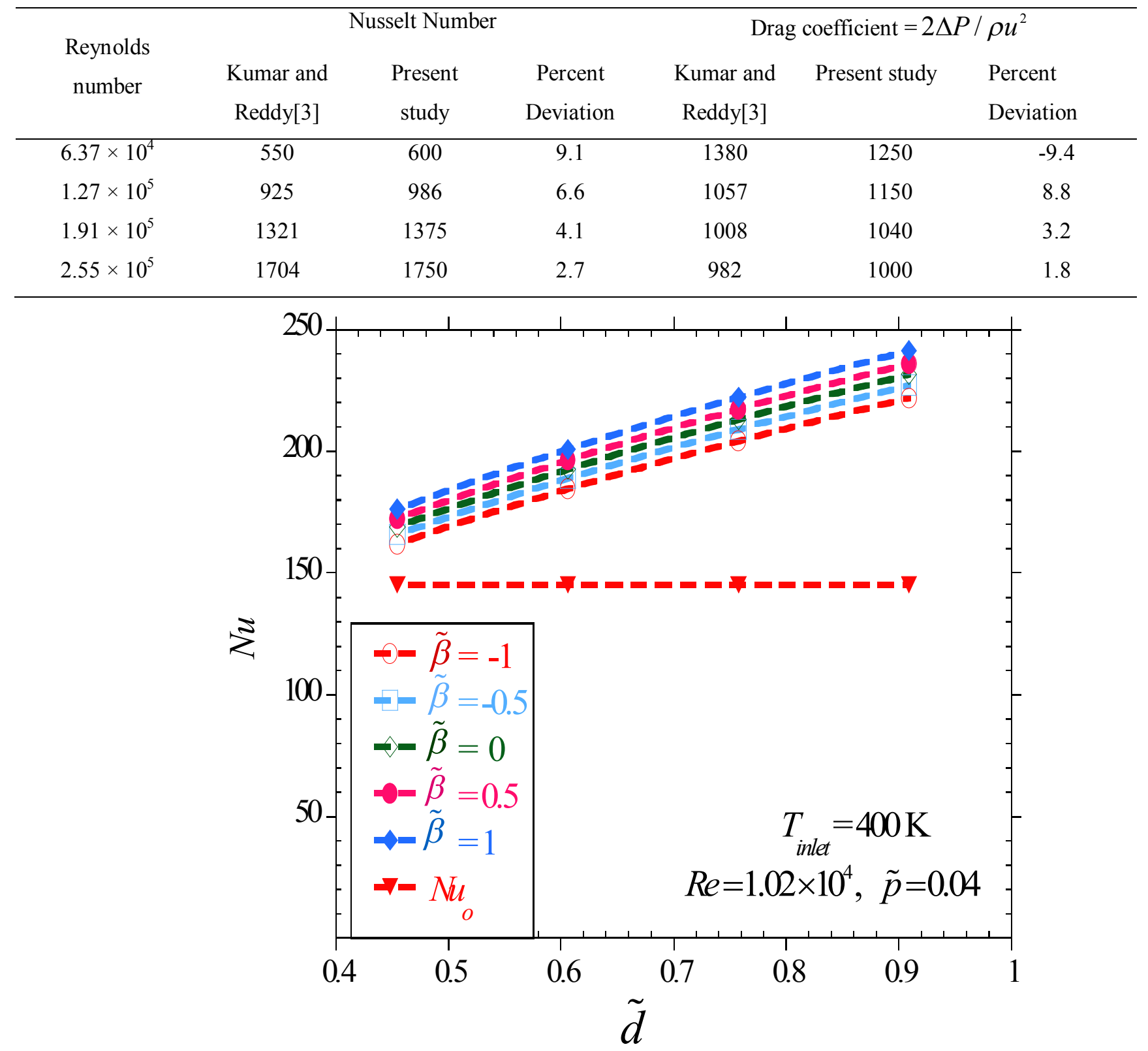

Fig. 6. Effect of insert size and orientation on heat transfer performance 


\subsection{Heat transfer and fluid friction performance}

\subsubsection{Effect of perforated plate size and orientation}

Fig. 6 shows the variation of Nusselt number with the normalised plate diameter, $\tilde{d}$ at $\tilde{p}=0.04$ and $R e$ $=1.02 \times 10^{4}$. As expected, the Nusselt number is shown to increase with the size of the plate. The figure further shows that, as the angle of orientation increases, the heat transfer performance slightly increases. This trend was observed at every value of plate spacing $(\tilde{p})$ and Reynolds number. The increase in heat transfer performance as the angle of orientation increases is mainly due to high fluid impingement on the lower half of the absorber tube at positive angles of orientation. The achievable heat transfer enhancement depends on the spacing, size and orientation of the plate as well as the Reynolds number.

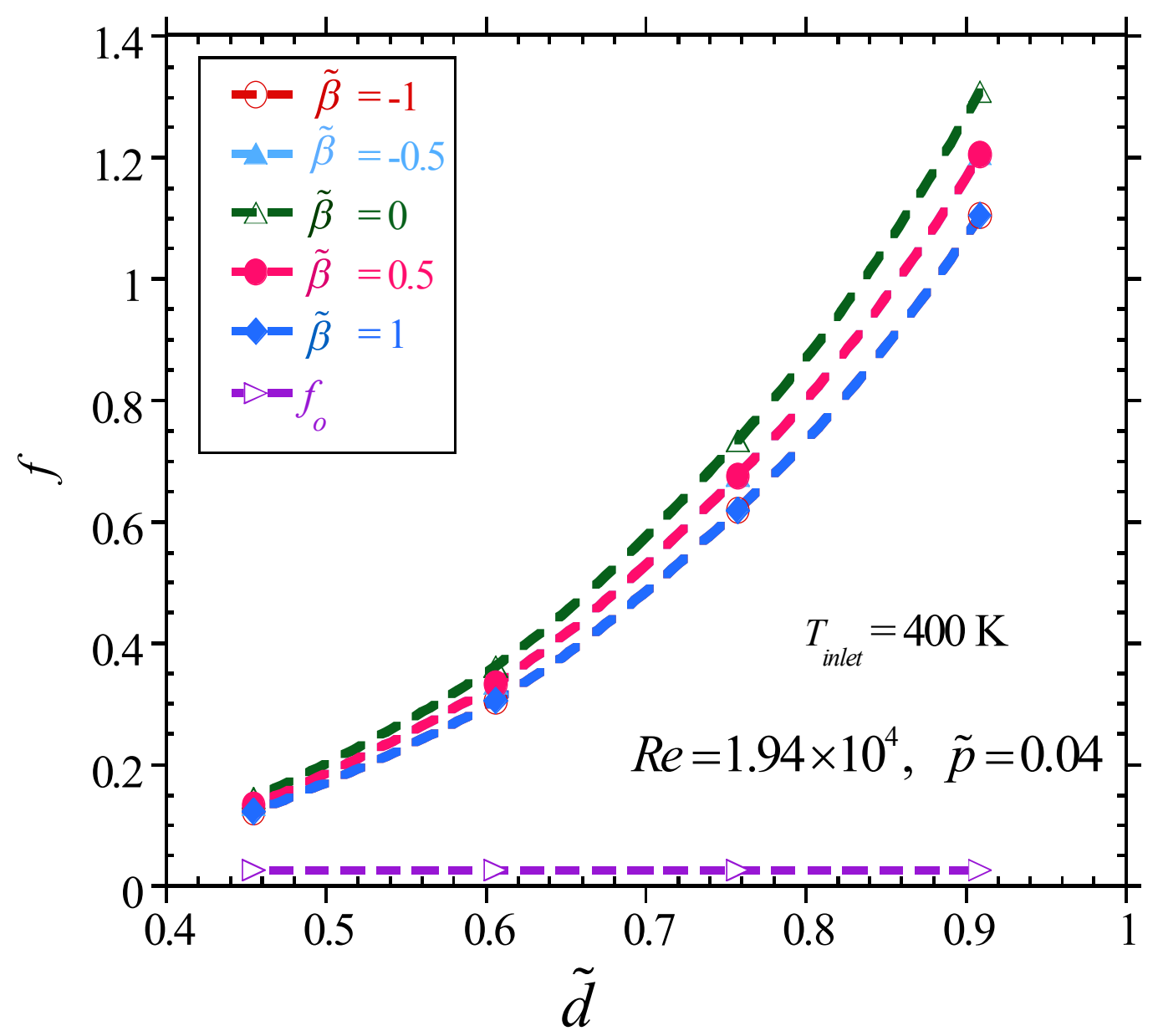

Fig. 7. Effect of insert size on fluid friction at different values of insert orientation 
Fig. 7 shows the effect of orientation angle and plate size on fluid friction. As expected, the increase in heat transfer performance due to increasing plate size is accompanied by increasing fluid friction. Fluid friction increases with the size of the plate due to increased blockage of the flow by the perforated plates. The fluid friction at $\tilde{\beta}=-0.5$ and $\tilde{\beta}=0.5$ for the same plate size, plate spacing and Reynolds number is the same as expected, since the resistance to fluid flow by the perforated plate at these orientations is the same. The same applies to the fluid friction at $\tilde{\beta}=-1$ and $\tilde{\beta}=1$.

Fig. 7, further shows that, the highest fluid friction occurs when $\tilde{\beta}=0$. The lowest fluid friction is at $\tilde{\beta}=1$ and $\tilde{\beta}=-1$. At $\tilde{\beta}=0$, the flow upstream of the plate remains perpendicular to the perforated plate thus high resistance to flow. When the plate is slanting at a given angle, the fluid "slips" over the plate and thus less friction. Also at $\tilde{\beta}=0$ the area open to the flow is also small compared to that at other values of $\tilde{\beta}$ for the same value of $\tilde{d}$.

In general, at all values of $\tilde{p}$ and Reynolds numbers, an increase in plate size provides better heat transfer performance but with an accompanying increase in fluid friction. As the angle of orientation increases, there is a slight increase in the heat transfer performance. Fluid friction is minimum at both $\tilde{\beta}=1$ and $\tilde{\beta}=-1$, while maximum heat transfer enhancement is achieved at $\tilde{\beta}=1$.

\subsubsection{Effect of plate spacing and Reynolds number}

Figs. 8 (a) and $8(\mathrm{~b})$ show the variation of Nusselt number with plate spacing and Reynolds number for $\tilde{d}=$ 0.91 and $\tilde{\beta}=1$ at a temperature of $400 \mathrm{~K}$ and $\tilde{d}=0.45$ and $\tilde{\beta}=1$ at a temperature $650 \mathrm{~K}$ respectively. The figures show that, as the spacing reduces the heat transfer performance increases. This is due to increase in flow impingement and improved fluid mixing as the plate spacing reduces. The figure also shows an increase in heat transfer performance as the Reynolds number increases due to a thinner boundary layer at higher Reynolds numbers. The same trend exists at other values of plate size, orientation and temperatures.

Due to significant variation of fluid properties as the temperature increases, at the same flow rate, Reynolds numbers increase significantly with increase in temperatures. Thus, at a given flow rate, higher fluid temperatures result in higher Reynolds numbers and higher heat transfer rates. This can be shown in Fig. 9, at the same flow rates the Reynolds numbers increase as the inlet temperature increases to $600 \mathrm{~K}$. Therefore, the Nusselt number increases as the fluid temperatures increase at a given flow rate. For the range of parameters considered, the use of perforated plates increases the heat transfer performance in the range $8-133 \%$ 

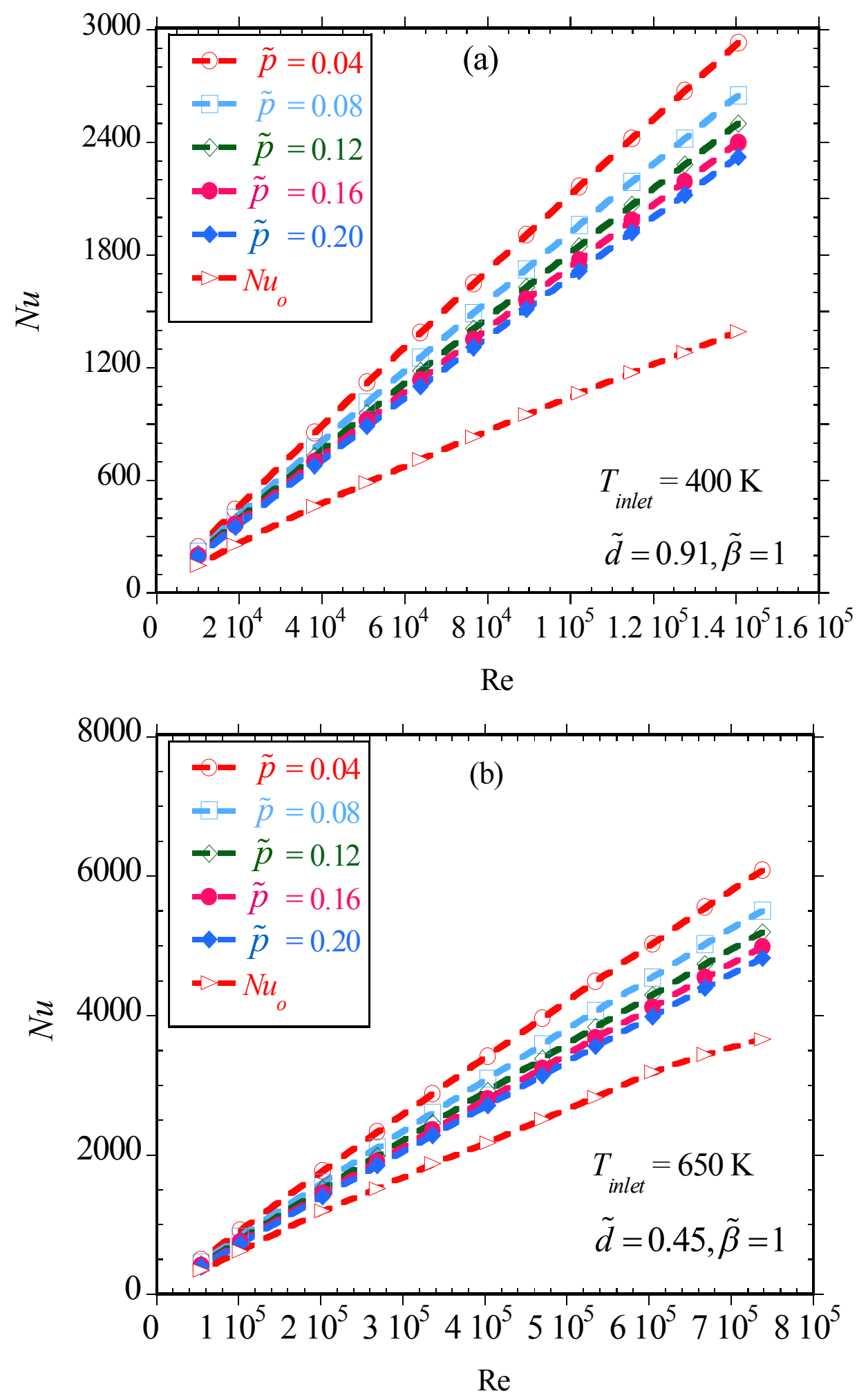

Fig. 8. Variation of heat transfer performance at different values of insert spacing with Reynolds number (a) At $\tilde{d}=0.91$ and $\tilde{\beta}=1$ for $400 \mathrm{~K}$ (b) At $\tilde{d}=0.45$ and $\tilde{\beta}=1$ for $650 \mathrm{~K}$ 


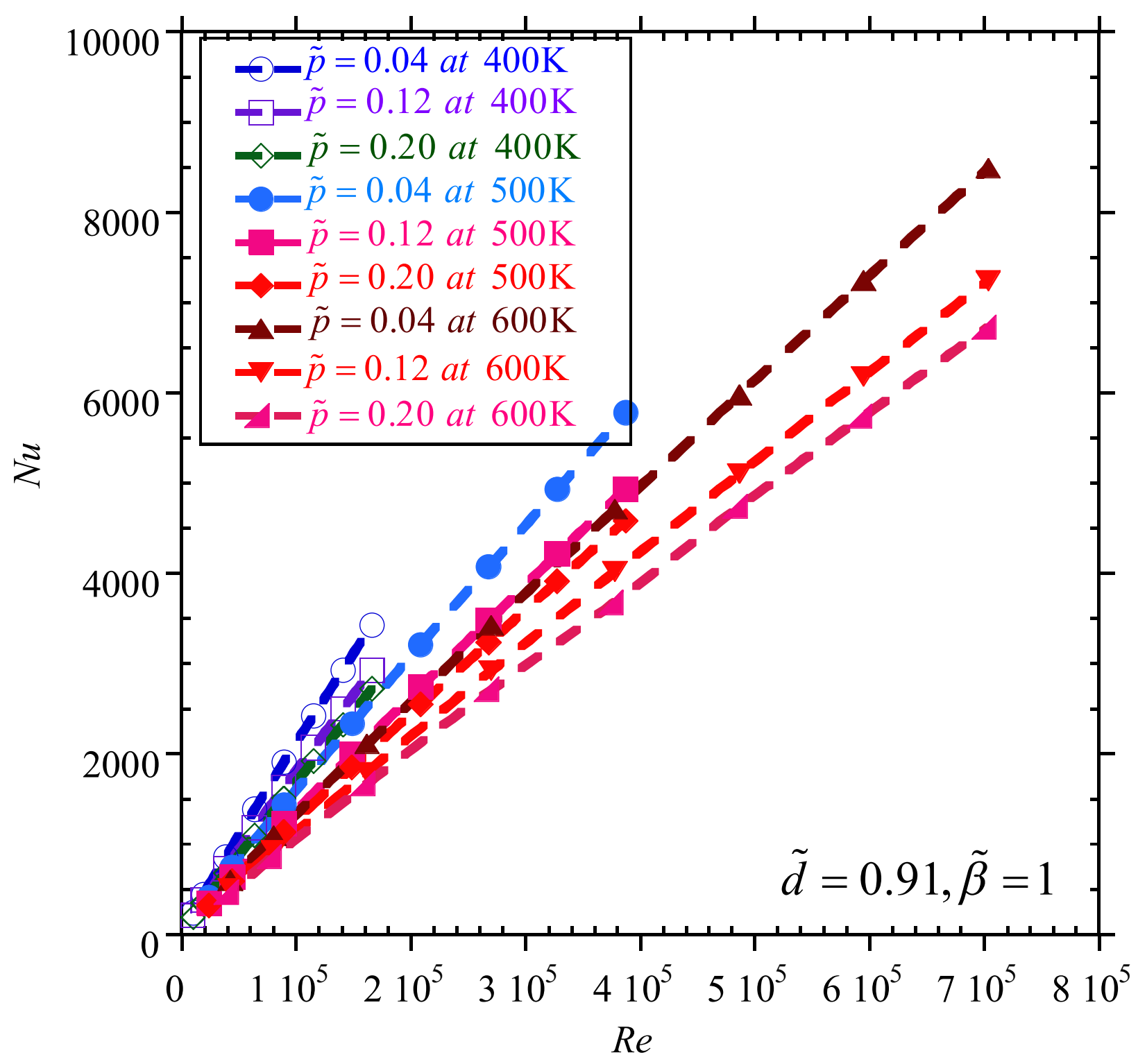

Fig. 9. Variation of heat transfer performance at different values of insert spacing with Reynolds number at different temperatures for $\tilde{d}=0.91$ and $\tilde{\beta}=1$.

depending on the size, orientation and spacing of the plate as well as the temperature and flow rate of the heat transfer fluid considered.

Fig. 10 shows the variation of friction factor with Reynolds number at different values of insert spacing for $\tilde{d}=0.91$ and $\tilde{\beta}=1$ at a temperature of $400 \mathrm{~K}$. As expected, lower values of insert spacing results in high fluid friction due to flow blockage by the increased number of plates per unit meter. The variation of friction factor with Reynolds number also exhibits the well-known trend. The same trend exists for other values of insert size orientation and temperature. Considering the fluid friction at different temperatures, Fig. 11 shows 


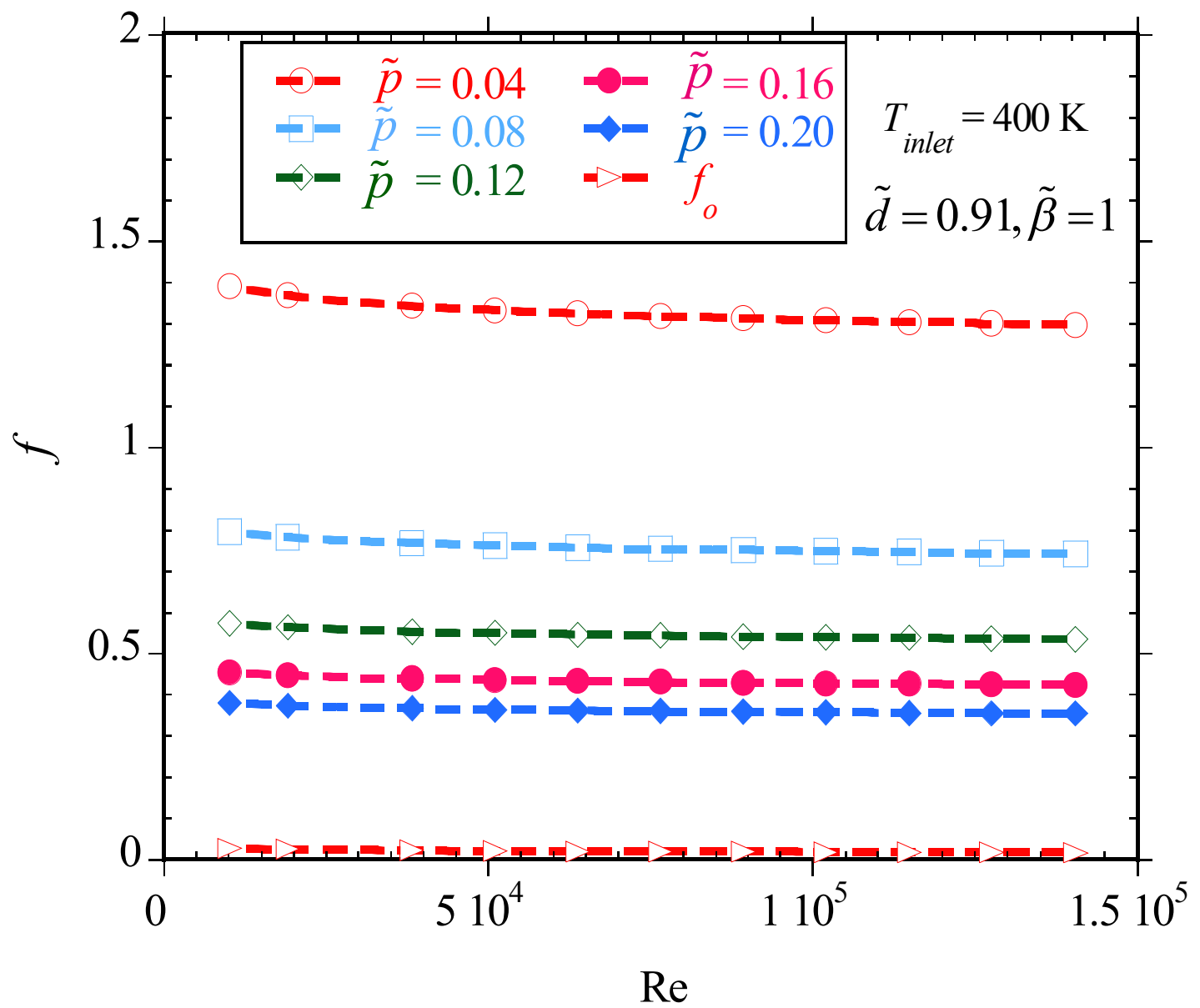

Fig. 10. Variation of friction factor with Reynolds number at different values of insert spacing at $\tilde{d}=0.91$ and $\tilde{\beta}=1$

the same trend with Reynolds number. However, lower temperatures result in slightly higher fluid friction at given values of insert spacing, insert size and insert orientation for the same flow rate due to the low Reynolds numbers. For the range of parameters considered, the fluid friction increases between 1.40 - 95 times compared to a receiver with a plain absorber tube, depending on the size, orientation and spacing of the inserts as well as the flow rate.

In general, smaller values of insert spacing will increase the heat transfer performance but with significant increase in fluid friction. Improvement in heat transfer performance can be achieved with lower fluid friction at higher values of spacing and lower values of insert size. For example at $\tilde{p}=0.20, \tilde{\beta}=1$ and insert size $\tilde{d}$ $=0.45$, the heat transfer increases $23-55 \%$ and friction factors increase in the range $1.40-3.5$ times in the range of Reynolds numbers considered. 


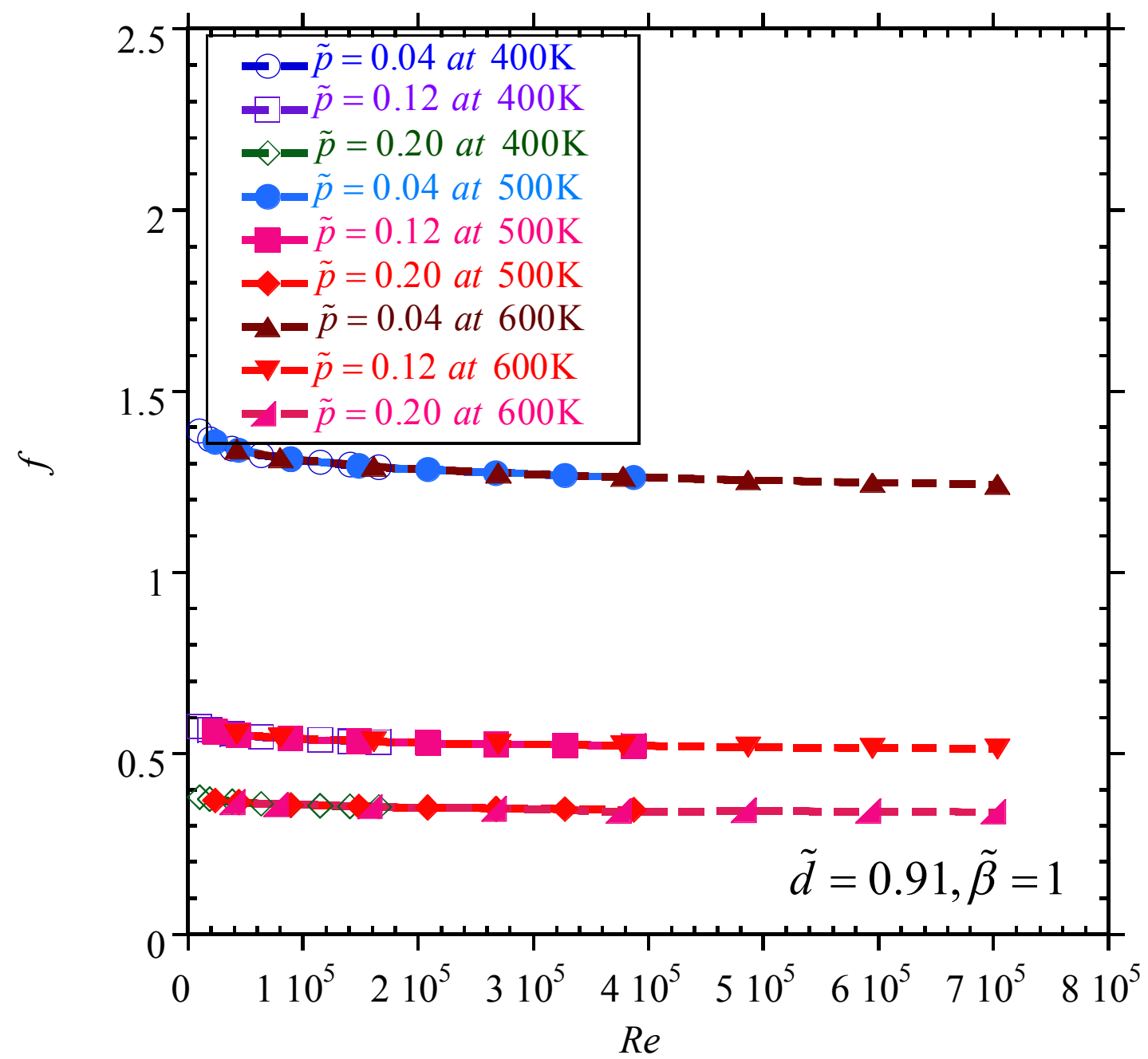

Fig. 11. Variation of fluid friction at different values of insert spacing with Reynolds number at different temperatures for $\tilde{d}=0.91$ and $\tilde{\beta}=1$.

\subsubsection{Empirical correlations for Nusselt number and fluid friction}

Based on the numerical simulations, correlations for the Nusselt number and fluid friction were obtained for the range of parameters considered using regression analysis.

The Nusselt number is correlated by

$$
N u=\frac{5.817 \operatorname{Re}^{0.9483} \operatorname{Pr}^{0.4050} \tilde{p}^{-0.1442} \tilde{d}^{0.4568}(1+0.0742 \tan \beta)}{1000}
$$

$R^{2}=0.998$ for this correlation. The correlation is within less than $\pm 15 \%$ for the range of parameters considered as shown in the Parity plot in Fig. 12. 


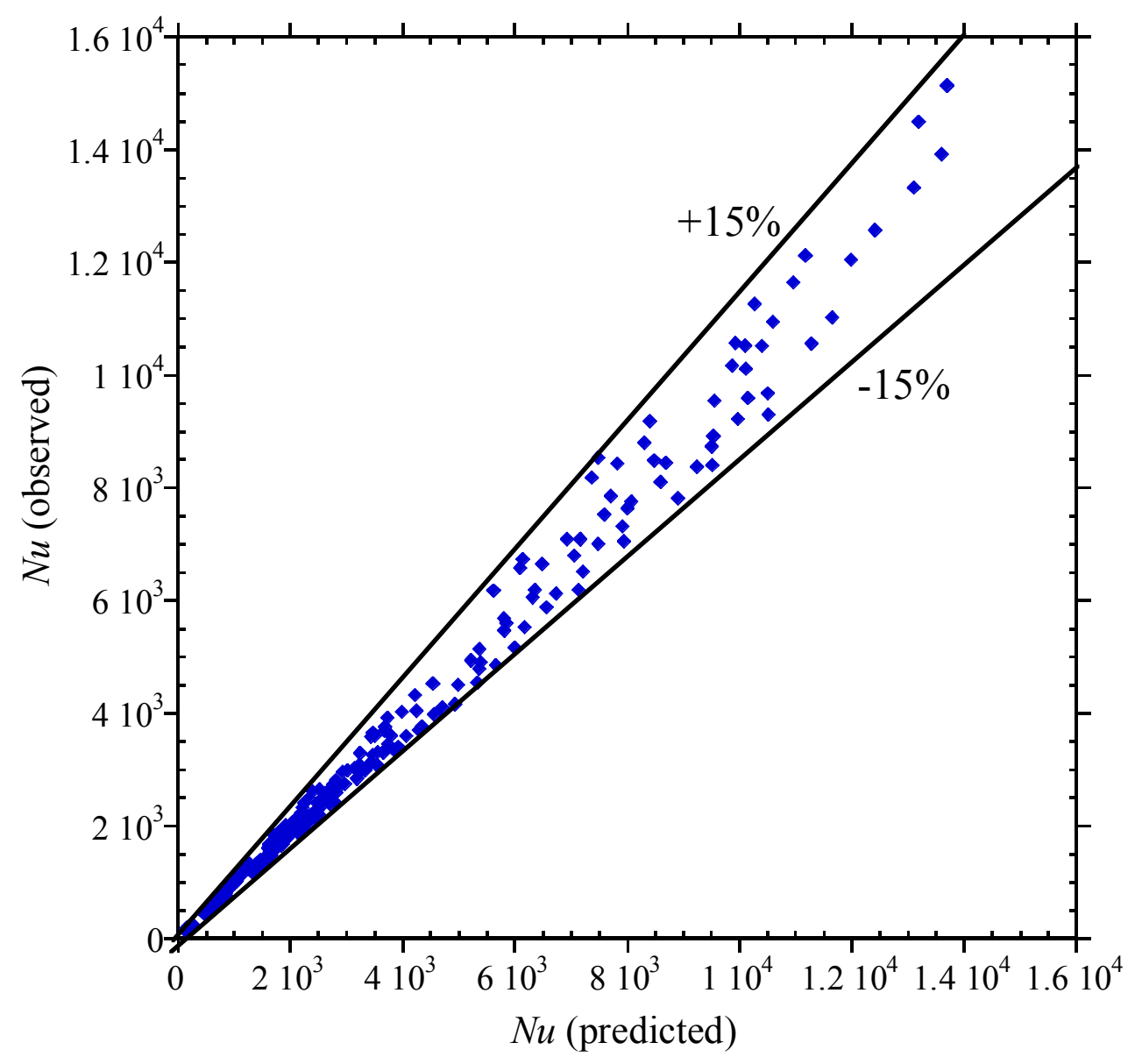

Fig. 12. Nusselt number parity plot

Fluid friction is correlated by

$f=0.1713 \operatorname{Re}^{-0.0267} \tilde{p}^{-0.8072} \tilde{d}^{3.1783}(1+0.08996 \sin \beta)$

For this equation $R^{2}=0.96$ and is valid within $\pm 18 \%$. The parity plot for $f$ is shown in Fig. 13 .

Eqs. (27) - (28) were derived with parameters in the range

$$
\begin{aligned}
& 1.0 \times 10^{4} \leq \operatorname{Re} \leq 7.38 \times 10^{5} \text { and } 9.29 \leq \operatorname{Pr} \leq 33.7 \\
& -30 \leq \beta \leq 30^{\circ} \\
& 0.04 \leq \tilde{p} \leq 0.20 \\
& 0.61 \leq \tilde{d} \leq 0.91 \\
& 400 \mathrm{~K} \leq \mathrm{T} \leq 650 \mathrm{~K}
\end{aligned}
$$




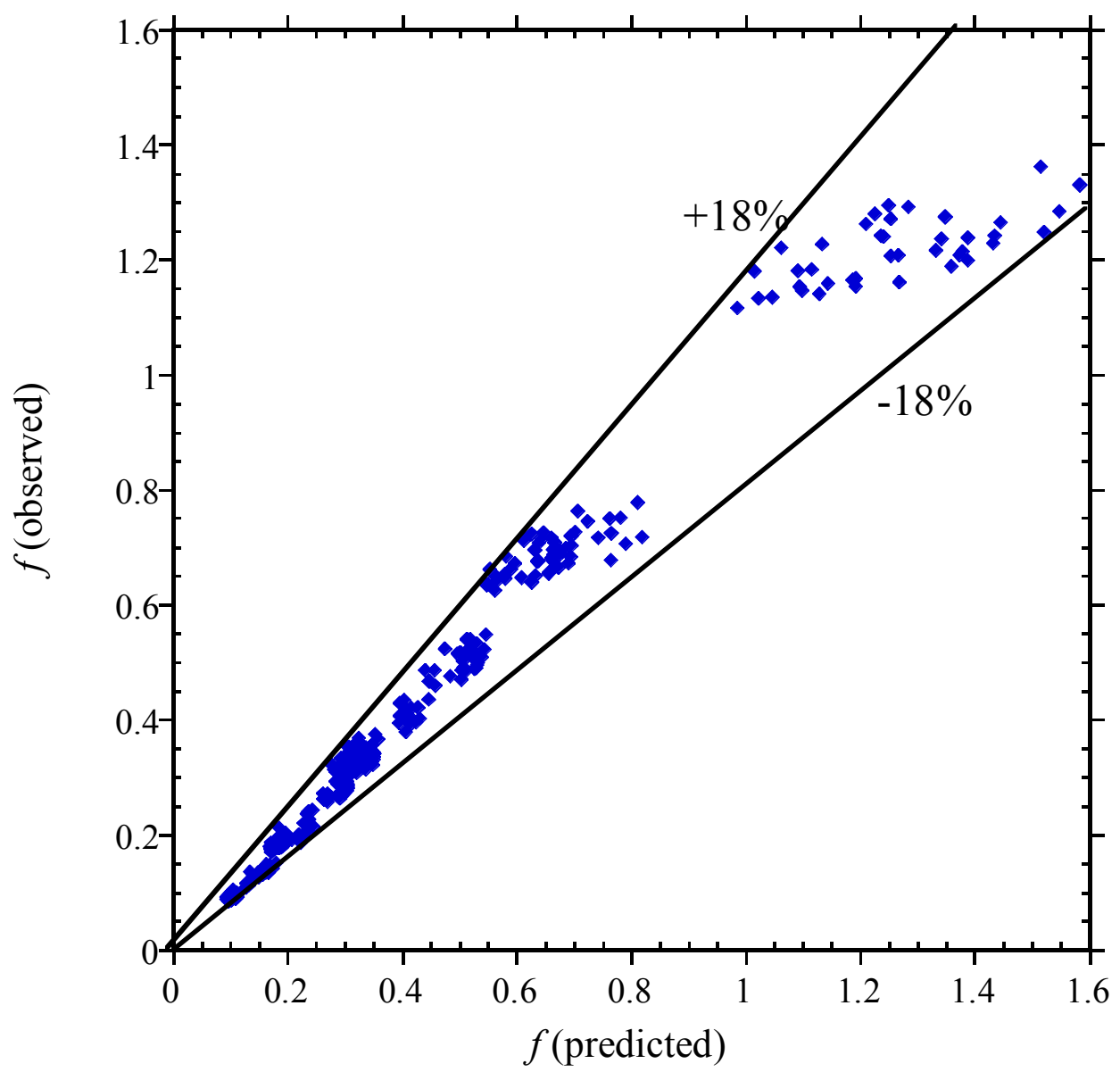

Fig. 13. Friction factor parity plot

The Reynolds number depends on the temperature considered. As such, the flow rates should be used to determine the velocities to be used in obtaining the Reynolds number for the correlations in Eqs. (25) - (28). The flow rates based on the inner diameter of the plain absorber tube used vary in the range $0.001368 \mathrm{~m}^{3} / \mathrm{s}$ to $0.01882 \mathrm{~m}^{3} / \mathrm{s}$ at each inlet temperature. In terms of mass flow rates, the above volumetric flow rates correspond to $1.14 \mathrm{~kg} / \mathrm{s}$ to $15.80 \mathrm{~kg} / \mathrm{s}$ at $400 \mathrm{~K}, 1.02 \mathrm{~kg} / \mathrm{s}$ to $14.05 \mathrm{~kg} / \mathrm{s}$ at $500 \mathrm{~K}, 0.87 \mathrm{~kg} / \mathrm{s}$ to $12.03 \mathrm{~kg} / \mathrm{s}$ at $600 \mathrm{~K}$ and $0.79 \mathrm{~kg} / \mathrm{s}$ to $10.86 \mathrm{~kg} / \mathrm{s}$ at $650 \mathrm{~K}$.

\subsubsection{Performance evaluation}

A preliminary measure for assessing the performance of heat transfer enhancement is the performance evaluation criteria (PEC) put forward by Webb [46]. According to Webb [46], the thermal enhancement factor is given by

$\chi=\left(N u / N u_{o}\right) /\left(f / f_{o}\right)^{1 / 3}$ 
Accordingly, the thermal enhancement factor should be 1 and greater, if pumping power is a concern. In such a case, the achieved heat transfer enhancement outweighs the increase in pumping power.

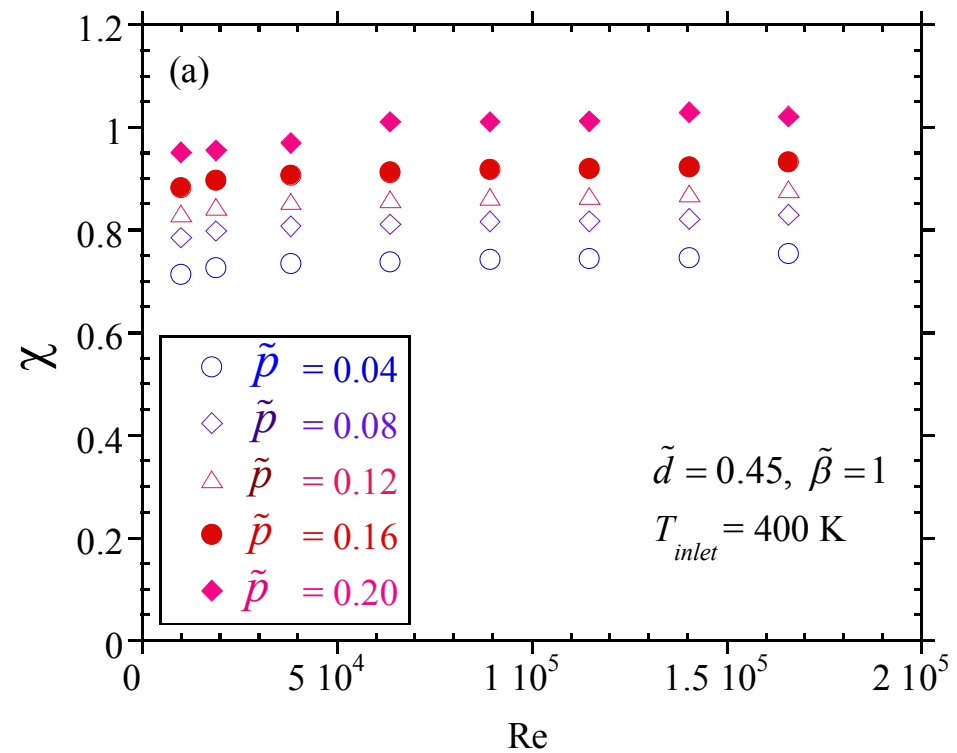

Fig. 14. Variation of thermal enhancement factor with Reynolds number (a) at different values of insert spacing for $\tilde{d}=0.45$ and $\tilde{\beta}=1$ at $400 \mathrm{~K}$. (b) at different values of insert

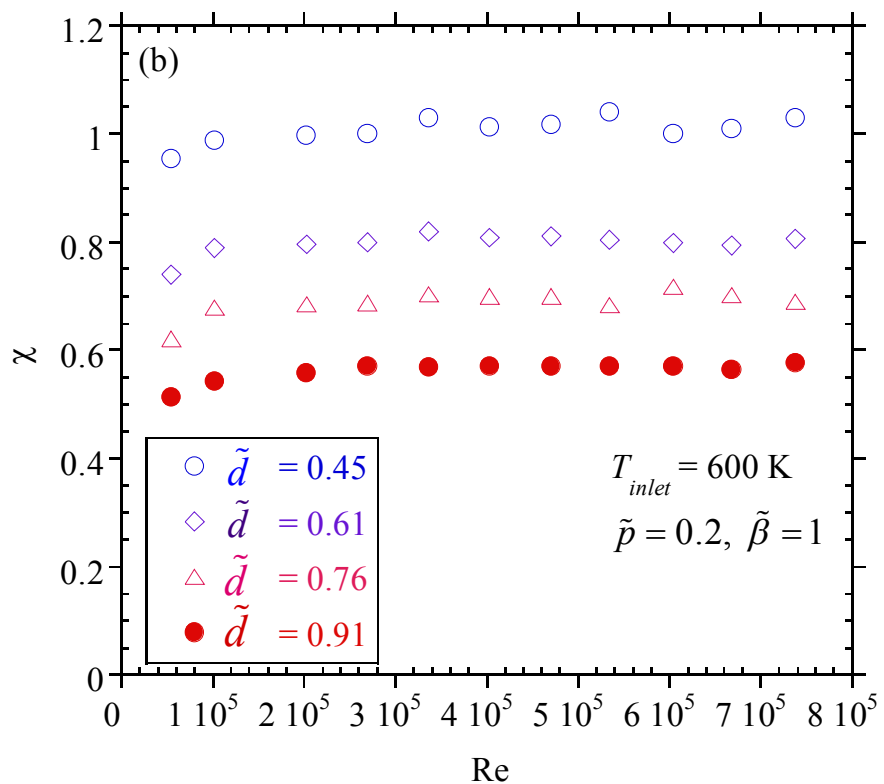

$\operatorname{Re}$

size for $\tilde{p}=0.20$ and $\tilde{\beta}=1$ at $600 \mathrm{~K}$

From this study, the thermal enhancement factor decreases significantly at any given Reynolds number as the insert spacing reduces as observed in Fig. 14(a). This is due to the significant increase in fluid friction at lower values of insert spacing. Fig. 14(b) shows the variation of the thermal enhancement factor with Reynolds number at $\tilde{p}=0.2$ and $\tilde{\beta}=1$, for different values of $\tilde{d}$ at $600 \mathrm{~K}$. The thermal enhancement factor is also shown to decrease significantly as the insert size increases. In this study, the thermal enhancement factor ranges from about $0.44-1.05$. Therefore, the use of lower insert spacing and larger inserts should be avoided. The highest values of the thermal enhancement factor exist at $\tilde{p}=0.2, \tilde{\beta}=1$ and $\tilde{d}=0.45$ at all temperatures considered. Insert spacing of $\tilde{p}=0.2$, orientation angle $\tilde{\beta}=1$ and insert size $\tilde{d}=0.45$ give reasonably high heat transfer enhancement and thermal enhancement factors for all the temperatures considered. The thermal enhancement factors for this set of parameters are in the range $0.95-1.05$ depending on the Reynolds number. 
To investigate the actual collector thermal performance, the actual gain in collector performance due to heat transfer enhancement should be compared with the corresponding increase in pumping power. Collector performance can be characterized in terms of collector's thermal efficiency which is a function of heat transfer rate and incident solar radiation. For comparison of a receiver with perforated plate inserts with a non-enhanced receiver, the thermal efficiency has been modified to include the pumping power. The modified thermal efficiency is function of the heat transfer rate, pumping power and incident solar radiation according to

$\eta_{t h, m}=\frac{\dot{Q}_{u}-\dot{W}_{p}}{A_{a} I_{b}}$

A similar evaluation was used by Muñoz and Abánades [13]. It is worth noting that this performance evaluation method was not originally included in the paper, one of the reviewers suggested it. The reviewer's input is duly acknowledged and appreciated.
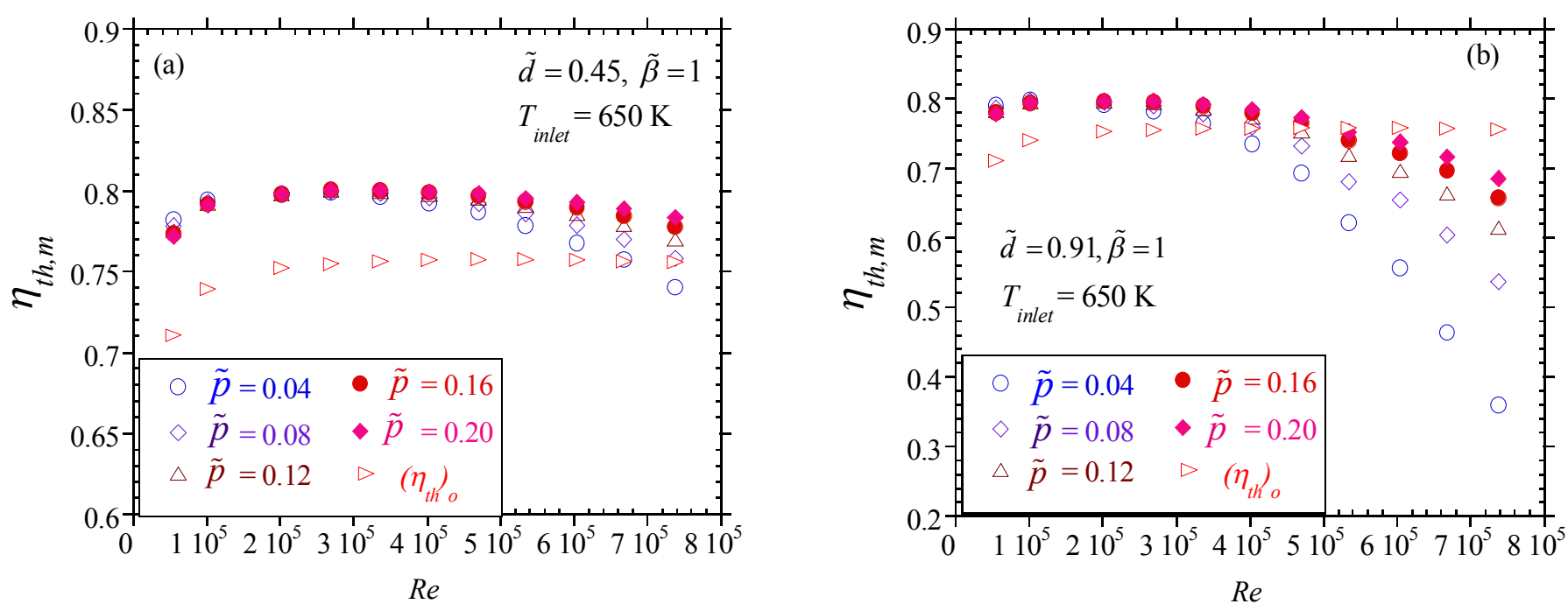

Fig. 15. Variation of collector modified thermal efficiency with Reynolds number at different values of insert spacing

In Eq. (30), $\dot{Q}_{u}=\dot{m} c_{p}\left(T_{\text {outlet }}-T_{\text {inlet }}\right)$ is the heat transfer rate; $\dot{W}_{p}=\dot{V} \Delta P$ is the pumping power; $A_{a}$ is collector's aperture area and $I_{b}$ is the incident solar radiation. Figs. 15(a) and 15(b) show the variation of the modified thermal efficiency with Reynolds number at different values insert spacing for $\tilde{d}=0.45$ and $\tilde{d}=0.91$ respectively. As shown in Figs. 15(a) and 15(b), the efficiency increases with the use of perforated plate inserts at each value of insert spacing and insert size up to some Reynolds number and then becomes lower than that of a non-enhanced tube. The efficiency of an enhanced tube will be lower than that of a non- 
enhanced tube when the gain in heat transfer rate becomes less than the required increase in pumping power. As seen in Fig. 15(a), the modified thermal efficiency is increased over a wider range of Reynolds numbers when the size of the insert is smallest. As the insert size increases, the efficiency increases over a smaller range of Reynolds number as shown in Fig. 15(b). At higher Reynolds numbers, the pumping power increases significantly and reduces the efficiency below that of a plain receiver tube. This same variation exists at the other temperatures considered in this study. At a given insert orientation angle, the increase in modified thermal efficiency depends on the size of the insert, the spacing between the inserts and the Reynolds number (or flow rate).

The modified thermal efficiency increases in the range $1.2-8 \%$ over the range of parameters considered depending on the insert size, spacing and Reynolds number. However, at all inlet temperatures, a flow rate lower than $0.01026 \mathrm{~m}^{3} / \mathrm{s}(8.61 \mathrm{~kg} / \mathrm{s}$ at $400 \mathrm{~K}, 7.66 \mathrm{~kg} / \mathrm{s}$ at $500 \mathrm{~K}, 6.56 \mathrm{~kg} / \mathrm{s}$ at $600 \mathrm{~K}$ and $5.92 \mathrm{~kg} / \mathrm{s}$ at $650 \mathrm{~K})$ gives an increase in efficiency in the range of $3-8 \%$ for insert spacing in the range $0.08 \leq \tilde{p} \leq 0.20$, when the insert size is in the range $0.45 \leq \tilde{d} \leq 0.61$. At higher flow rates, increase in efficiency is still feasible, however, the value of spacing should be higher and the size of the insert should be smaller as shown in Fig. 15 (a). At lower flow rates (lower than $0.00855 \mathrm{~m}^{3} / \mathrm{s}$ ), increase in efficiency is possible at most values of insert spacing and insert size since the pumping power increase is not significant compared to the gain in performance.

The increase in efficiency is mainly due to the increased heat transfer performance as well as reduced receiver losses. Heat transfer enhancement reduces absorber tube temperatures, the reduction in absorber tube temperature results in lower coating emissivity, thus lower radiation losses.

It is worth noting, that the use of the performance evaluation criteria at constant pumping power comparison given in Eq. (29) does not give an accurate account of the actual performance of the parabolic trough receiver with heat transfer enhancement. This is probably because it does not account for additional gain in performance from reduced absorber tube temperatures and the subsequent reduction in radiation heat losses. Moreover, with parabolic trough receivers the gain in performance with heat transfer enhancement might be much higher than the increase in pumping power. 

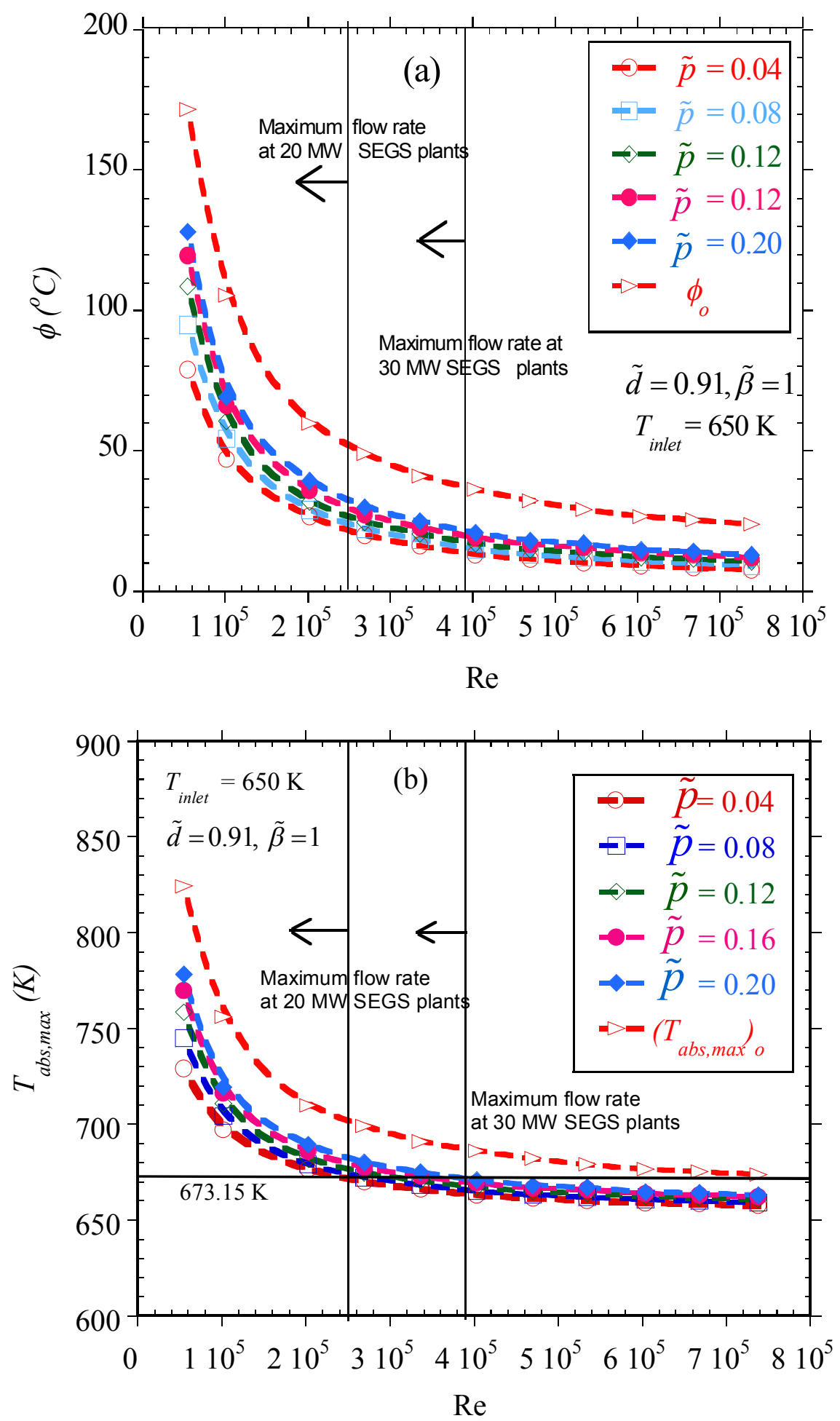

Fig. 16. (a) Variation of temperature gradients with Reynolds number and insert spacing (b) Variation of peak temperatures in the receiver's absorber tube with Reynolds number and insert spacing 


\subsubsection{Absorber tube temperatures}

Increased heat transfer performance is expected to reduce the temperature gradients in the receiver's absorber tube. Fig. 16(a) shows the variation of absorber tube temperature gradient with Reynolds number and insert spacing at a temperature of $650 \mathrm{~K}$. Where $\phi=\left(T_{a b s, \text { max }}-T_{a b s, \text { min }}\right)$ is the difference between the maximum temperature of the absorber tube and minimum temperature of the absorber tube. The absorber temperature gradients are shown to reduce with increasing Reynolds numbers and decreasing insert spacing. In general, the higher the heat transfer enhancement, the lower the absorber tube temperature gradient. Large reductions in the absorber tube temperature gradients occur at lower insert spacing, maximum angle of orientation and maximum insert size. For the range of parameters considered, the absorber tube temperature gradients are reduced between 5-67\%. Significant reductions in the absorber tube's circumferential temperature gradients are observed at lower Reynolds numbers. As such, heat transfer enhancement will be very beneficial in reducing absorber tube temperature gradients for applications where low mass flow rates are desirable.

Absorber tube peak temperatures are also a concern to avoid degradation of the heat transfer fluid especially at high fluid temperatures. Therefore, any reduction in these peak temperatures will be essential to improving the receiver's performance and minimising degradation of the heat transfer fluid. As shown in Fig. 16(b), the use of perforated plate inserts reduces the absorber tube maximum temperature and can keep them at levels lower than $673.15 \mathrm{~K}$ even in the range of flow rates at commercial plants [47]. The maximum flow rates at the $20 \mathrm{MW}$ SEGS plants is about $0.0063 \mathrm{~m}^{3} / \mathrm{s}(3.63 \mathrm{~kg} / \mathrm{s}$ evaluated at $650 \mathrm{~K})$, at the $30 \mathrm{MW}$ SEGS plants, the maximum flow rate is about $0.01009 \mathrm{~m}^{3} / \mathrm{s}(5.84 \mathrm{~kg} / \mathrm{s}$ evaluated at $650 \mathrm{~K})$ [47].

Generally, heat transfer enhancement is shown to reduce the temperatures, temperature gradients in the receiver's absorber tube. In addition to reducing the stresses in the tube, reduced temperatures increase receiver performance due to lower radiation losses. The radiation losses reduce due to a lower temperature difference between the glass cover and absorber tube as well as lower emissivity of the absorber tube at lower temperatures. Moreover, the exergetic performance of the receiver will improve due to a lower finite temperature difference in the absorber tube and thus reduced heat transfer irreversibility.

\subsection{Thermodynamic performance of the receiver with perforate plate insert}

The ratio of entropy generation due to heat transfer enhancement to the entropy generation for a nonenhanced device $\left(N_{s, e n}=S_{g e n} /\left(S_{g e n}\right)_{o}\right.$ is used to characterize the thermodynamic performance. $N_{s, \text { en }}$ should be less than 1 for better thermodynamic performance [26]. 

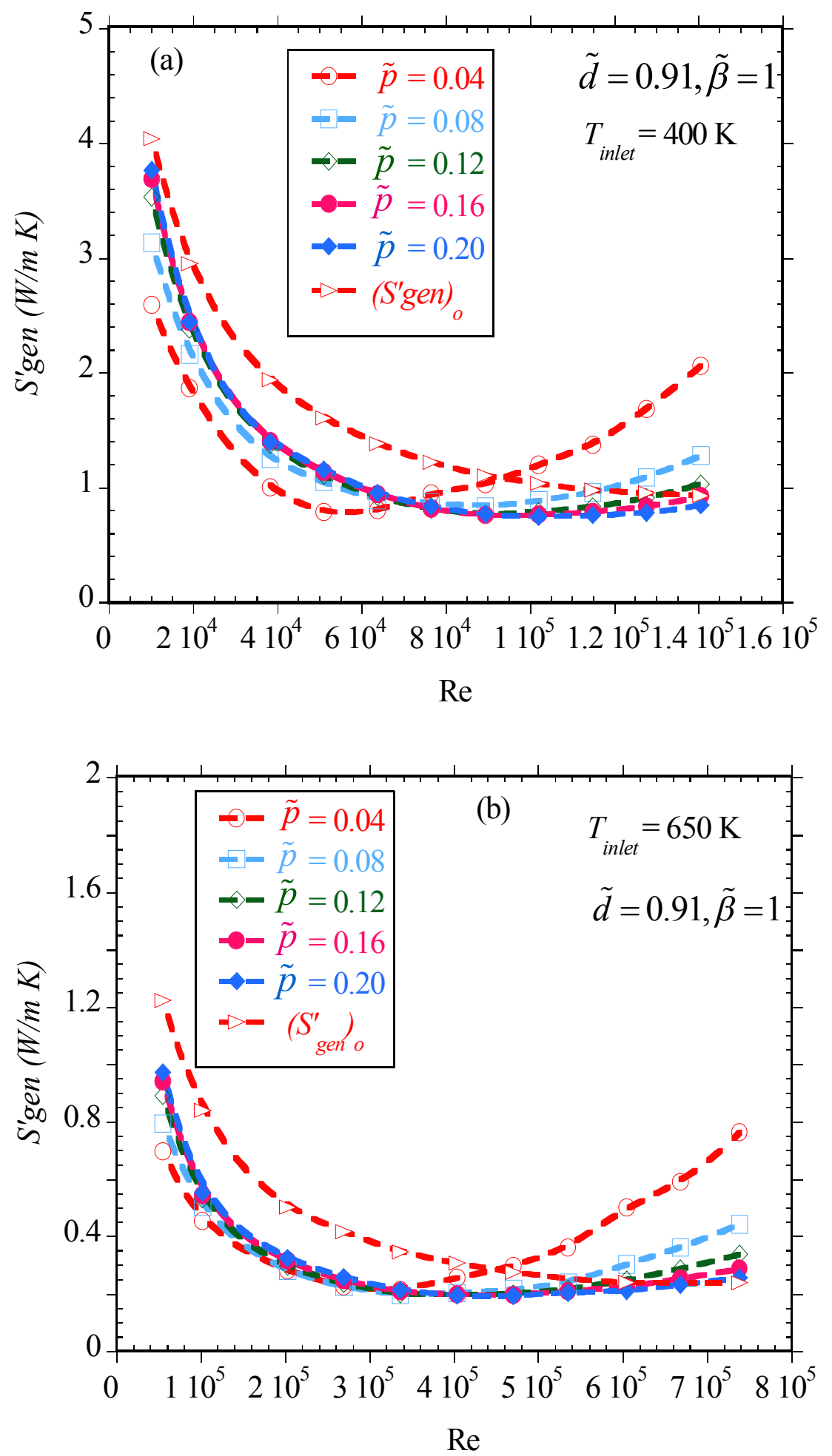

Fig. 17. Variation of entropy generation with Reynolds numbers at different values of insert spacing at $\tilde{d}=0.91$ and $\tilde{\beta}=1$ (a) $T_{\text {inlet }}=400 \mathrm{~K}(\mathrm{~b}) T_{\text {inlet }}=650 \mathrm{~K}$ 
At low Reynolds numbers the heat transfer irreversibility is the dominant source of irreversibility. Such that increasing the diameter of the plate or reducing the spacing of the consecutive plates reduces the entropy generation rate. As the Reynolds number increases, the heat transfer irreversibility reduces but the fluid friction irreversibility begins to increase. At higher Reynolds numbers, the fluid friction irreversibility increases and becomes the dominant source of irreversibility. Such that increasing the diameter of the plate or reducing the spacing gives higher values of entropy generation rate. Therefore, there is a value of Reynolds number at which entropy generation is a minimum at every value of $\tilde{p}, \tilde{d}$ and $\tilde{\beta}$ at any given heat transfer fluid temperature as shown in Figs. 17 (a) for $\tilde{d}=0.91$ and $\tilde{\beta}=1$ when the heat transfer fluid temperature is $400 \mathrm{~K}$ and Fig. 17 (b) when the temperature is $650 \mathrm{~K}$.

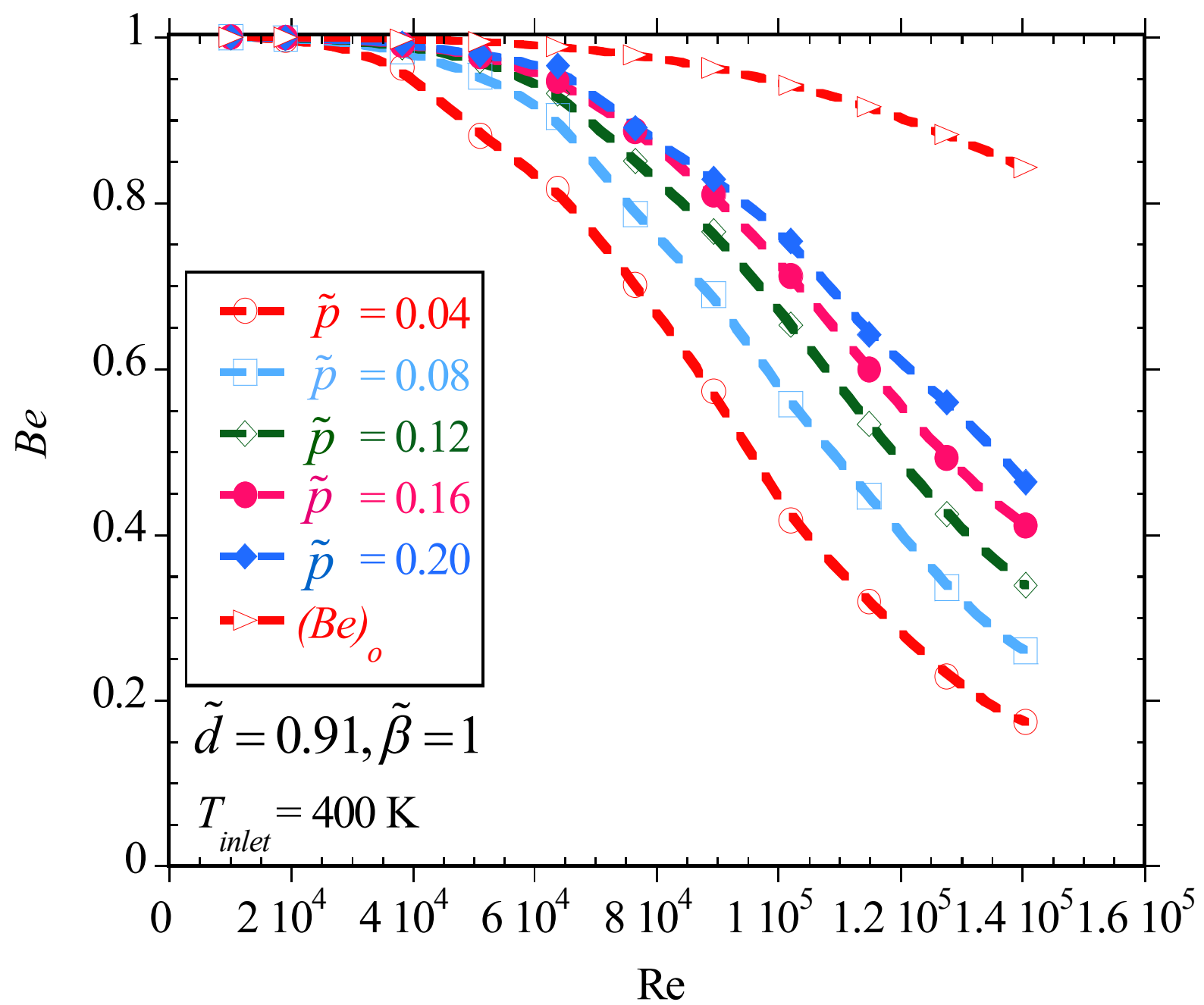

Fig. 18. Variation of the Bejan number with Reynolds numbers at different values of insert spacing 

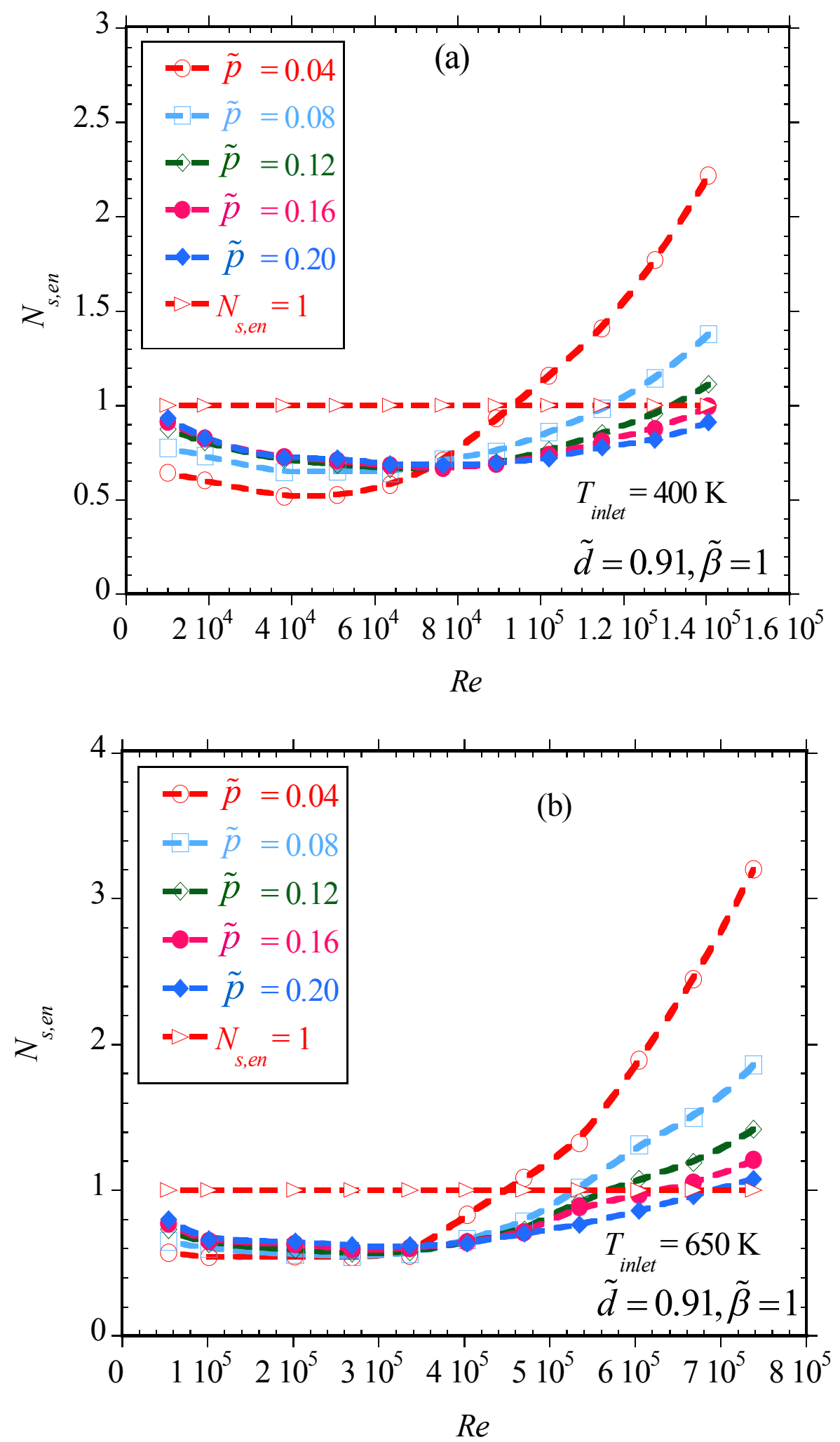

Fig. 19. Variation of the entropy generation ratio with Reynolds numbers at different values of insert spacing at $\tilde{d}=0.91$ and $\tilde{\beta}=1$ (a) $T_{\text {inlet }}=400 \mathrm{~K}$ (b) $T_{\text {inlet }}=650 \mathrm{~K}$ 
The Bejan number, $B e$, shows the contribution of the heat transfer and fluid friction irreversibility. The Bejan number is the ratio of the heat transfer irreversibility to the total entropy generation rate. As shown in Fig. 18, the Bejan number is high at low Reynolds numbers and reduces as Reynolds numbers increase at every value of insert spacing. The Figure also shows the Bejan number to reduce as the insert spacing reduces due to improved heat transfer and accompanying reduction of the finite temperature difference.

Figs. 19 (a) and 19 (b) show the plots $N_{s, e n}$ with Reynolds number for different values of insert spacing at $\tilde{d}=0.91$ and $\tilde{\beta}=1$ for temperatures of $400 \mathrm{~K}$ and $650 \mathrm{~K}$ respectively. The figure shows that, at a given value of insert spacing there is a Reynolds number beyond which $N_{s, e n}$ becomes greater than 1.0. The use of inserts above this Reynolds number is undesirable since more available work will be lost compared to a plain receiver. In this work, flow rates less than $0.01205 \mathrm{~m}^{3} / \mathrm{s}(\dot{m}=10.12 \mathrm{~kg} / \mathrm{s}$ at $400 \mathrm{~K}, \dot{m}=8.99 \mathrm{~kg} / \mathrm{s}$ at $500 \mathrm{~K}$, $\dot{m}=7.69 \mathrm{~kg} / \mathrm{s}$ at $600 \mathrm{~K}$ and $\dot{m}=6.96 \mathrm{~kg} / \mathrm{s}$ at $650 \mathrm{~K}$ ) ensure entropy generation ratios less than 1.0 for all values of insert spacing, insert size, plate orientation and heat transfer fluid temperature. The maximum reduction in entropy generation rate obtained for the range of parameters considered was about $52.7 \%$.

\section{CONCLUSION}

In the present study, a numerical investigation was carried to investigate the thermal, fluid friction and thermodynamic performance of a parabolic trough receiver with centrally placed perforated plate inserts.

From the study, the Nusselt number and friction factor are strongly dependent on the spacing and size of the insert as well as flow Reynolds number. For the range of Reynolds numbers, temperatures and geometrical parameters considered, the Nusselt number increases about $8-133.5 \%$ with friction factor penalties in the range 1.40 - 95 times compared to a receiver with a plain absorber tube while the thermal enhancement factors are in the range $0.44-1.05$.

The use of thermal enhancement factors for performance evaluation was shown to be unsuitable for the evaluation of the enhanced parabolic trough receivers. It does not take into account the increase in performance from reduced receiver losses due to lower emissivity and lower absorber tube temperatures. The modified thermal efficiency of the collector is a more suitable performance evaluation tool because it takes into consideration the actual gain in receiver performance and the corresponding increase in pumping power.

The use of perforated plate inserts is shown to increase the modified thermal efficiency of the receiver in the range $1.2-8 \%$ depending on the insert spacing, insert size and Reynolds number. The modified thermal efficiency increases in the range of $3-8 \%$ for insert spacing ranging from $0.08 \leq \tilde{p} \leq 0.20$ and insert size in the range $0.45 \leq \tilde{d} \leq 0.61$ for flow rates lower than $0.01026 \mathrm{~m}^{3} / \mathrm{s}$ at all inlet temperatures. This flow rate 
corresponds to the following mass flow rates evaluated at different temperatures: $8.61 \mathrm{~kg} / \mathrm{s}$ at $400 \mathrm{~K}, 7.66$ $\mathrm{kg} / \mathrm{s}$ at $500 \mathrm{~K}, 6.56 \mathrm{~kg} / \mathrm{s}$ at $600 \mathrm{~K}$ and $5.92 \mathrm{~kg} / \mathrm{s}$ at $650 \mathrm{~K}$.

Significant reductions in absorber tube temperature gradients and peak temperatures were achieved. The maximum reduction in absorber tube temperature gradients was about $67 \%$. As far as safety of the tube is concerned, the reduction in absorber tube's temperature gradients is shown to be beneficial for applications requiring low flow rates where temperature gradients are higher than $50 \mathrm{~K}$. Reduction in absorber tube temperatures also plays a significant role in reducing radiation losses. Thus reducing temperature gradients to values lower than $50 \mathrm{~K}$ will further improve the performance of the receiver provided the gained performance is not less than the increase in pumping power.

The use of inserts is also shown to improve the thermodynamic performance of the receiver by minimizing the entropy generation rates below a given flow rate. Overall, volumetric flow rates lower than $0.01205 \mathrm{~m}^{3} / \mathrm{s}$ were found to give entropy generation rates lower than those of a receiver with a plain absorber tube for all perforated plate geometrical parameters and temperatures considered. The maximum reduction in the entropy generation rate was about $52.7 \%$.

\section{ACKNOWLEDGEMENT}

The funding received from NRF, TESP, and Stellenbosch University/University of Pretoria, SANERI/SANEDI, CSIR, EEDSM Hub and NAC is duly acknowledged and appreciated.

\section{RERENCES}

[1] Kalogirou S. Solar energy engineering: processes and systems. 1st ed. Oxford, UK: Elsevier, Academic Press, 2009.

[2] Price H, Lüpfert E, Kearney D, Zarza E, Cohen G, Gee R et al. Advances in parabolic trough solar power technology. Sol Energy Eng 2002;124:109-25.

[3] Ravi Kumar K, Reddy KS. Thermal analysis of solar parabolic trough with porous disc receiver. Appl Energy 2009;86:1804-12.

[4] Burkholder F, Kutscher C. Heat-loss testing of Solel's UVAC3 parabolic trough receiver. NREL 2008;NREL/TP - 550-42394:1-19.

[5] Burkholder F, Kutscher C. Heat loss testing of Schott's 2008 PTR70 parabolic trough receiver. NREL 2009;NREL/TP - 550-45633:1-58. 
[6] Lüpfert E, Riffelmann K, Price H, Burkholder F, Moss T. Experimental analysis of overall thermal properties of parabolic trough receivers. Sol Energy Eng 2008;130:021007.

[7] Dudley EV, Kolb JG, Mahoney AR, Mancini T, R., Sloan M, Kearney D. Test results: SEGS LS-2 solar collector. Sandia National Laboratory 1994;SAND94-1884.

[8] Dudley EV, Evans RL, Mathews WC. Test results: Industrial Solar Technology parabolic trough solar collector. Sandia National Laboratory 1995;SAND94-1117.

[9] Padilla RV, Demirkaya G, Goswami DY, Stefanakos E, Rahman MM. Heat transfer analysis of parabolic trough solar receiver. Appl Energy 2011;88:5097-110.

[10] SunShot Initiative-High-concentration low cost parabolic trough system for baseload CSP, available at: http://www1.eere.energy.gov/solar/sunshot/csp baseload skyfuel.html

. U S Department of Energy 2012;February 2013.

[11] Mwesigye A, Bello-Ochende T, Meyer JP. Numerical investigation of entropy generation in a parabolic trough receiver at different concentration ratios. Energy 2013;53:114-27.

[12] Almanza R, Lentz A, Jiménez G. Receiver behavior in direct steam generation with parabolic troughs. Sol Energy 1998;61:275-8.

[13] Muñoz J, Abánades A. Analysis of internal helically finned tubes for parabolic trough design by CFD tools. Appl Energy 2011;88:4139-49.

[14] Moens L, Blake DM. Mechanism of hydrogen formation in solar parabolic trough receivers . J Sol Energ-T ASME 2010;132:031006.

[15] Li J, Wang Z, Lei D, Li J. Hydrogen permeation model of parabolic trough receiver tube. Sol Energy 2012;86:1187-96.

[16] Forristall R. Heat transfer analysis and modeling of a parabolic trough solar receiver implemented in Engineering Equation solver. NREL October 2003;NREL/TP-550-34169:1-145.

[17] Cheng ZD, He YL, Cui FQ, Xu RJ, Tao YB. Numerical simulation of a parabolic trough solar collector with nonuniform solar flux conditions by coupling FVM and MCRT method. Sol Energy 2012;86:1770-84.

[18] He Y, Xiao J, Cheng Z, Tao Y. A MCRT and FVM coupled simulation method for energy conversion process in parabolic trough solar collector. Renew Energ 2011;36:976-85.

[19] Lüpfert E, Pfänder M, Schiricke B, Eck M. Determination of temperature distribution on parabolic trough receivers. 13th International symposium on concentrating solar power and chemical energy technologies 2006;A1-S6.

[20] Wu Z, Li S, Yuan G, Lei D, Wang Z. Three-dimensional numerical study of heat transfer characteristics of parabolic trough receiver. Appl Energy 2014;113:902-11. 
[21] Wang P, Liu DY, Xu C. Numerical study of heat transfer enhancement in the receiver tube of direct steam generation with parabolic trough by inserting metal foams. Appl Energy 2013;102:449-60.

[22] Ravi Kumar K, Reddy KS. Numerical Investigation of Energy-Efficient Receiver for Solar Parabolic Trough Concentrator. Heat Transfer Eng 2008;29:961-72.

[23] Cheng ZD, He YL, Cui FQ. Numerical study of heat transfer enhancement by unilateral longitudinal vortex generators inside parabolic trough solar receivers. Int J Heat Mass Trans 2012;55:5631-41.

[24] Manglik RM. Heat Transfer Enhancement. In: Bejan A, Kraus AD, editors. Heat Transfer Handbook, Hoboken, New Jersey: John Wiley \& Sons; 2003, p. 1029-1130.

[25] Bergles AE. Techniques to enhance heat transfer. In: Hartnett JP, and Cho YI, editors. Handbook of heat transfer, New York: McGraw-Hill; 1998, p. 11.71-11.76.

[26] Bejan A. Entropy generation minimization: the method of thermodynamic optimization of finite-size systems and finite-time processes. Boca Raton, Fla.: CRC Press, 1996.

[27] ANSYS® Academic research, release 14.5, ANSYS FLUENT, theory guide, ANSYS, Inc.

[28] Versteeg HK, Malalasekera W. An introduction to computational fluid dynamics: the finite volume method. 2nd ed. Harlow, England: Pearson/Prentice Hall, 2007.

[29] Shih T, Liou WW, Shabbir A, Yang Z, Zhu J. A new k-€ eddy viscosity model for high reynolds number turbulent flows. Comput Fluids 1995;24:227-38.

[30] ANSYS® Academic research, release 14.5, ANSYS FLUENT user's guide, ANSYS, Inc.

[31] Haque SME, Rasul MG, Khan MMK, Deev AV, Subaschandar N. Numerical modelling for optimizing flow distribution inside an electrostatic precipitator. Math Comput Simulat 2007;1:255-61.

[32] Weber LJ, Cherian MP, Allen ME, Muste M. Headloss characteristics for perforated plates and flat bar screens. IIHR Technical Report March, 2000;411:1-95.

[33] NREL. SolTrace optical modelling software. SolTrace 2012;2012.7.9.

[34] García-Valladares O, Velázquez N. Numerical simulation of parabolic trough solar collector: Improvement using counter flow concentric circular heat exchangers. Int J Heat Mass Trans 2009;52:597609.

[35] Mullick SC, Nanda SK. An improved technique for computing the heat loss factor of a tubular absorber. Solar Energy 1989;42:1-7.

[36] Le Roux WG, Bello-Ochende T, Meyer JP. Operating conditions of an open and direct solar thermal Brayton cycle with optimised cavity receiver and recuperator. Energy 2011;36:6027-36. 
[37] Le Roux WG, Bello-Ochende T, Meyer JP. Optimum performance of the small-scale open and direct solar thermal Brayton cycle at various environmental conditions and constraints. Energy 2012;46:42-50.

[38] Kock F, Herwig H. Entropy production calculation for turbulent shear flows and their implementation in cfd codes. Int J Heat Fluid Fl 2005;26:672-80.

[39] Bejan A. A study of entropy generation in fundamental convective heat transfer. J Heat Transfer $1979 ; 101: 718-25$.

[40] Ko TH, Wu CP. A numerical study on entropy generation induced by turbulent forced convection in curved rectangular ducts with various aspect ratios. Int Commun Heat Mass Transfer 2009;36:25-31.

[41] S V, Patankar. Numerical heat transfer and fluid flow . 1st ed. Washington D.C.: Taylor \& Francis, 1980 .

[42] SYLTHERM 800 heat transfer fluid:product techinical data.

http://www.dow.com/heattrans/products/synthetic/syltherm.htm 2012;2012.

[43] Wu Z, Li S, Yuan G, Lei D, Wang Z. Three-dimensional numerical study of heat transfer characteristics of parabolic trough receiver. Appl Energy 2014;113:902-11.

[44] S C, G C, R C, D B, H P. Parabolic trough organic Rankine cycle solar power plant. NREL/CP-55037077 204:1-2.

[45] Çengel YA, Ghajar AJ. Heat and mass transfer: fundamentals \& applications. 4th ed. New York: McGraw-Hill, 2011.

[46] Webb RL. Performance evaluation criteria for use of enhanced heat transfer surfaces in heat exchanger design. Int J Heat Mass Transfer 1981;24:715-26.

[47] Cohen G, E., Kearney D,W., Kolb G, J. Final report on the operation and maintenance improvement program for concentrating solar power plants. . Sandia National Laboratories 1999;SAND99-1290.:1-186. 